\title{
A review on flicker-free ac-dc LED drivers for single-phase and three-phase ac power grids
}

\author{
Ignacio Castro, Member, IEEE, Aitor Vazquez, Member, IEEE, Manuel Arias, Member, IEEE, Diego G. Lamar, \\ Senior Member, IEEE, Marta M. Hernando, Senior Member, IEEE and Javier Sebastian, Senior Member, IEEE. \\ e-mail: castroig@utrc.utc.com
}

\begin{abstract}
Light-Emitting Diodes (LEDs) are coming strongly into the lighting market due to their advantages over conventional lighting solutions: energy efficient, controllable in both light and color, long lifetime, lack of a warm-up period and high power density. Some of these advantages will make LED light sources to be more than just a lightbulb, being able to transmit data, control light color, hue and intensity or even detect people in indoor environments. Nevertheless, these advantages attributed to LED capabilities are, in reality, achieved thanks to the LED driver. The present work reviews the current stateof-the-art strategies to drive LEDs from ac power grids with special emphasis into removing the most limiting component from the point of view of the lifetime, which is the electrolytic capacitor, while achieving a flicker-free performance of the light output of the LED driver. Moreover, it focuses on analyzing the required regulations, challenges and applicability of LED drivers in both single-phase and three-phase ac power grids.
\end{abstract}

Keywords- Ac-dc power conversion, Power factor correction, Single-phase, Three-phase, LED driver, capacitorless, flicker-free.

\section{INTRODUCTION}

Light-Emitting Diodes (LEDs) are becoming increasingly ubiquitous across all aspects of illumination products due to their reliability, long lifetime, energy efficiency and low maintenance requirements. In fact, some of these advantages will make LED light sources to be more than just a lightbulb, being able to transmit data [1]-[3], control light color, hue and intensity or even detect people in indoor environments [4], [5]. Nevertheless, these advantages attributed to LED capabilities are, in reality, achieved by the LED driver, which can be defined as the power supply that controls and ensures an adequate light output of the LEDs.

In summary, the main electrical particularity of an LED is that significant current is only able to go across it in one direction, as any other diode. Hence, the LED can be considered as a non-linear load that follows a V-I curve, as depicted in Fig. 1 for three different commercial LEDs. As can be seen, the curves are extremely similar to each other, and emphasis should be put at the higher knee-voltages (i.e., $\mathrm{V}_{\gamma 1}$, $\mathrm{V}_{\gamma 2}$ and $\mathrm{V}_{\gamma 3}$ ) when compared with traditional Schottky diodes. After reaching this value, the current rapidly increases causing

This work was supported in part by the Spanish Government under Project MINECO-17-DPI2016-75760-R, in part by the Principality of Asturias under Severo Ochoa grant BP14-142 and Project GRUPIN2018 JAVIER SEBASTIAN, and in part by European Regional Development Fund (ERDF) grants.

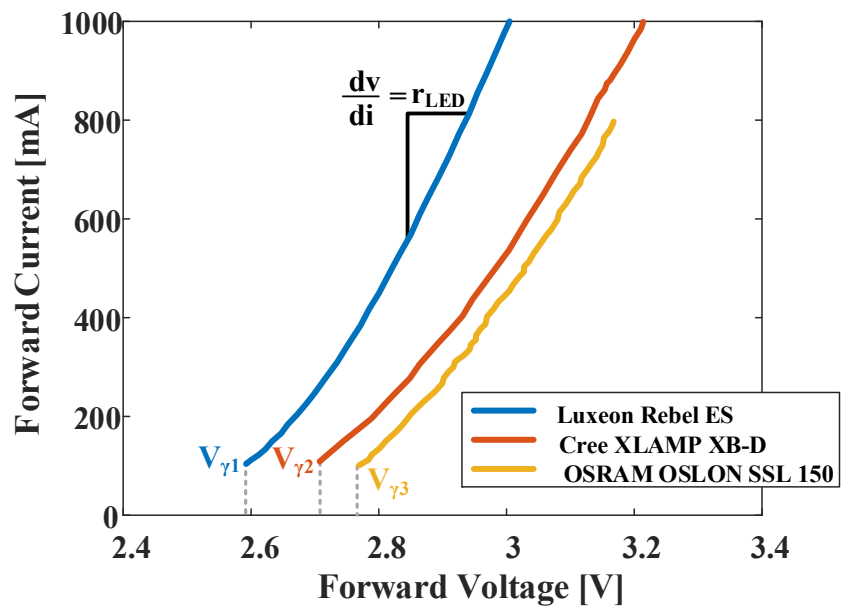

Fig. 1. V-I diagram for some commercial LED from the biggest manufacturers: Lumiled [9], Cree [10] and OSRAM [11].

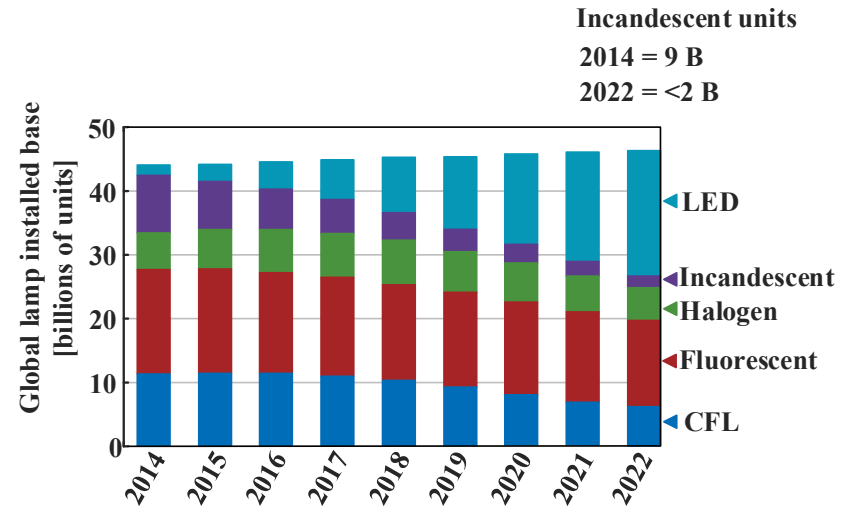

Fig. 2. Expectations of global installed base of lamps in terms of lightsource technology [12].

the luminous flux to fluctuate accordingly, following an almost linear relationship [6], [7]. The aforementioned reasons imply that an LED load should be controlled in terms of its forward current instead of its forward voltage. Therefore, the luminous intensity of the light can be controlled online to be adequate to the requirements of the user, the online variation of this parameter in terms of a reference is referred in literature as dimming [8].

The main application for LEDs is to replace inefficient lighting technologies in residential and commercial environments, which traditionally have primary access to the ac power grid, in accordance to their aforementioned 


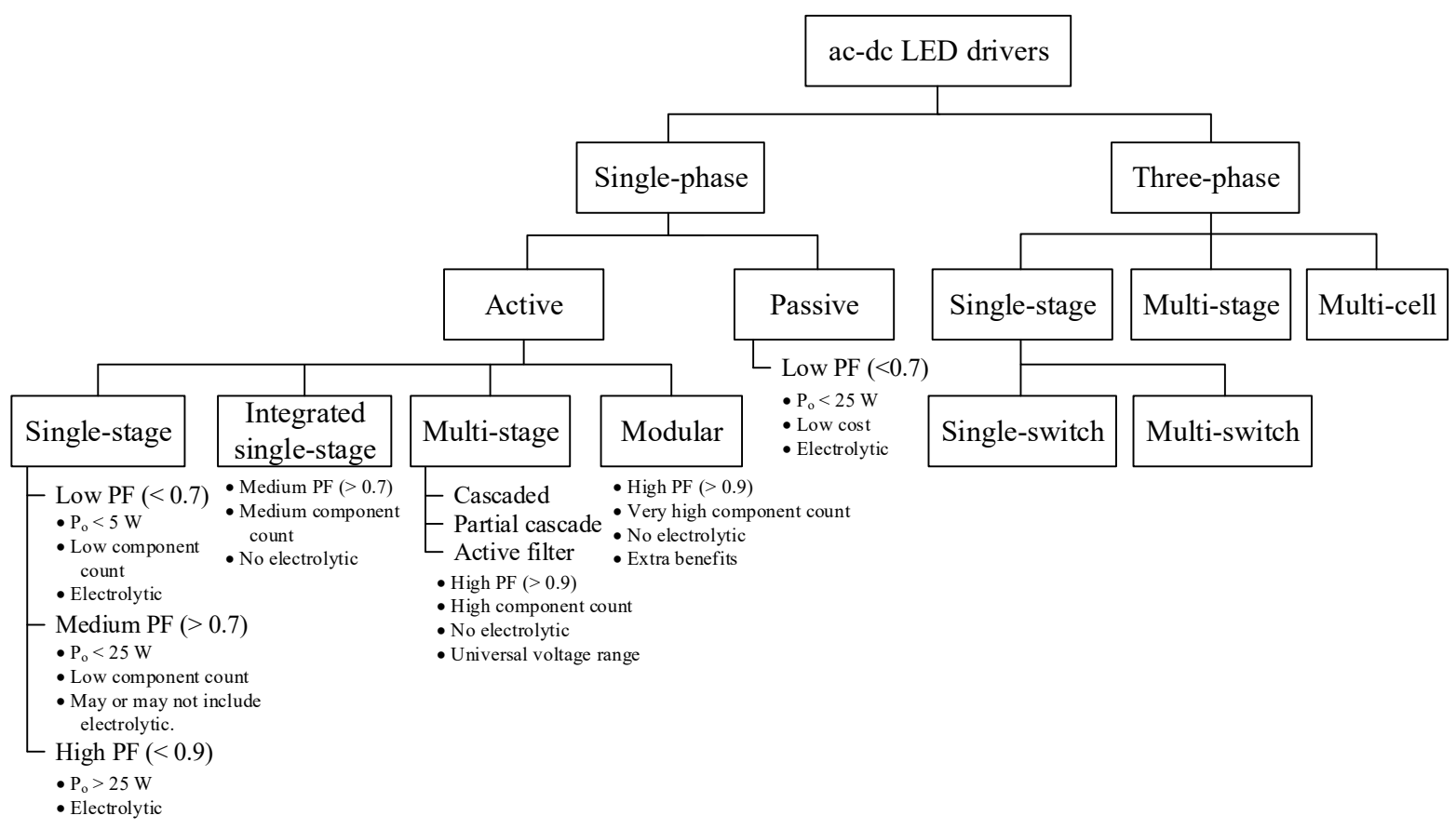

Fig. 3. Classification of ac-dc LED drivers for both single-phase and three-phase ac power grids.

advantages. In that sense, Fig. 2 shows the expectations for the lighting market until 2022. As can be seen LEDs are supposed to replace incandescent light and even start to replace Compact Fluorescent Lights (CFL) by that date.

Considering the inherent behaviour of the LEDs as a diode, only allowing the current to go across it in one direction, it is necessary to use an ac-dc converter to ensure that the LEDs are driven with an adequate dc current. The reason behind requiring this power conversion comes from the fast currentlight response from the LEDs, which could replicate the sinusoidal current from the grid at double the mains frequency causing an undesirable visible flicker to occur. In fact, this requirement has made the driving of LEDs from the mains an important research topic in a wide range of power [13]. In accordance to previous literature, an ac-dc LED driver needs to be: efficient, compact, operate in universal voltage range, comply with specific regulations for LED drivers (discussed in Section II), have a lifetime comparable to that of LEDs, and control the current across the LED load in order to perform dimming and achieve an adequate light output. Taking into consideration the aforementioned characteristics, Fig. 3 shows at a glance, the proposed classification for ac-dc LED drivers for both single-phase and three-phase ac power grids in terms of the number of power conversion stages used. A distinction between single-phase ac-dc LED drivers and three-phase ac-dc LED drivers is made taking into account that three-phase ac-dc LED drivers are proposed for high power LED loads (i.e., > $300 \mathrm{~W}$ ). In addition, single-phase solutions are divided between active and passive, considering the latter are more prone to be used for LED lamps (i.e., $<25 \mathrm{~W}$ ), whereas active solutions are used for both LED lamps and LED luminaires (i.e., > $25 \mathrm{~W}$ ). The different solutions will be further detailed along Section
III for single-phase ac-dc LED drivers and Section IV for three-phase ac-dc LED drivers, considering the latest trends with a special focus on the aforementioned requirements that an ac-dc LED driver should comply with. The last section will be dedicated to the conclusions that can be extracted from the comprehensive study carried out on the latest trends for ac-dc LED drivers after reviewing and classifying over 200 publications.

\section{REGULATIONS AND RECOMMENDATIONS FOR AC-DC LED DRIVERS}

The regulations that an LED driver needs to comply with are to be understood before discussing which solutions are the most appropriate. This section focuses on specific regulations and recommendations for LED drivers, such as: the ENERGY STAR ${ }^{\circledR}$ program requirements product specification for luminaries, harmonic standard (i.e. IEC 61000-3-2) and flicker regulations and metrics.

\section{A. ENERGY STAR®}

ENERGY STAR $\AA$ summarizes a series of requirements for LED lighting products to achieve their seal of approval, including the LED load and the ac-dc LED driver. In addition, the regulation differentiates between two kinds of LED loads: LED lamps and LED lighting fixtures (i.e., LED luminaires), and excludes a series of products, such as, solid state retrofits, high bay fixtures, outdoor street and area lighting and party or entertainment lighting [14]. Nonetheless, it still covers a wide spectrum of LED lighting products both in residential and commercial environments.

Of the aforementioned requirements, the first one is directed to lamps intended to replace incandescent light bulbs [15], whereas the second is intended for most lighting 
Table I. LED driver requirements, in accordance to ENERGY STAR ${ }^{\circledR}$ [16].

The LED package(s) / LED module(s) / LED array(s), including those incorporated into LED light engines or retrofit kits, shall meet the following $\mathrm{L}_{70}$ lumen maintenance life values:

- $\quad \mathrm{L}_{70} \geq 25,000$ hours for indoor.

Rated Lifetime $\quad$ - $\quad \mathrm{L}_{70} \geq 35,000$ hours for outdoor.

- $\mathrm{L}_{70} \geq 50,000$ hours for inseparable luminaires.

Note: $\mathrm{L}_{70}$ defines the elapsed operating time over which the LED light source will maintain a $70 \%$ of its initial light output.

\begin{tabular}{ll}
\hline Source Start Time & $\begin{array}{l}\text { Light source shall remain continuously illuminated within 1 second of application of electrical } \\
\text { power. }\end{array}$ \\
\hline Power Factor & $\begin{array}{l}\text { Total luminaire input power } \leq 5 \text { watts: } \mathrm{PF} \geq 0.5 . \\
\text { Total luminaire input power }>5 \text { watts: } \mathrm{PF} \geq 0.7 .\end{array}$ \\
\hline $\begin{array}{l}\text { Standby Power } \\
\text { Consumption }\end{array}$ & Luminaires shall not draw power in the off state. \\
\hline Operating Frequency & Lamp light output shall have a frequency $\geq 120 \mathrm{~Hz}$. \\
\hline Transient Protection & $\begin{array}{l}\text { Ballast or driver shall comply with ANSI/IEEE C62.41.1-2002 and ANSI/IEEE C62.41.2-2002, } \\
\text { Category A operation. } \\
\text { The line transient shall consist of seven strikes of a } 100 \mathrm{kHz} \text { ring wave, } 2.5 \mathrm{kV} \text { level, for both } \\
\text { common mode and differential mode. }\end{array}$ \\
\hline Dimming Performance & $\begin{array}{l}\text { The luminaire and its components shall provide continuous dimming from } 100 \% \text { to 20\% of light } \\
\text { output. } \\
\text { Note: This only applies for certified dimmable luminaires. }\end{array}$ \\
\hline Audible noise & Luminaire shall not emit noise above 24 dBA at 1 meter or less at the minimum output. \\
\hline \hline
\end{tabular}

products intended for direct connection to the power grid with an input power below $250 \mathrm{~W}$ [16]. Specifically, Table I lists the requirements that the ac-dc LED driver needs to meet in order to comply with ENERGY STAR $^{\circledR}$. From this list, it should be noted that the most restrictive constraints are the rated life and the Power Factor (PF). The first, because it requires the ac-dc LED driver to last longer than $10,000 \mathrm{~h}$, which is the rated lifetime of the most restrictive component frequently used in ac-dc LED drivers, the electrolytic capacitor [17]. The second, since its compliance drastically reduces the possible topologies that can be used for its design, as an almost sinusoidal current waveform in phase with the voltage needs to be guaranteed at the input of the LED driver. It should be noted that those ac-dc LED drivers that have an input power of less than $5 \mathrm{~W}$ and a PF of more than 0.5 would fall into the low PF subcategory previously introduced in Fig. 3.

\section{B. Harmonic injection standard, IEC 61000-3-2}

Over the last few decades, the rise of non-linear loads connected to the grid has caused the amount of low frequency harmonics to increase. The increase is principally caused by the usage of inadequate ac-dc converters that demand nonsinusoidal currents with a low PF. In fact, a diode bridge followed by an electrolytic capacitor is commonly used in low cost applications causing the current to be demanded as short duration current peaks.

In order not to cause the quality of the grid to decrease, the International Electrotechnical Commision (IEC) released several regulations to limit the low frequency harmonic injection from electronic equipment to the grid. For the scope of this work, the IEC 61000-3-2 regulation, which limits the harmonic injection in equipment that draws input currents of $\leq 16$ A per phase, is going to be considered as an indispensable requirement in the design of ac-dc LED drivers. The regulation details how the low frequency harmonics of the input current (i.e., the first 40 from the fundamental frequency) need to be limited and measured depending on the classification summarized in [18]. According to this classification, lighting equipment falls under the Class $\mathrm{C}$ category for single-phase ac power grids. However, the regulation is not clear at stating under which category falls a balanced three-phase equipment for lighting applications as it falls in both Class A and Class C. Consequently, this specific equipment will be considered as Class $\mathrm{C}$ due to its more restrictive nature over Class A.

Furthermore, Class C differentiates two scenarios depending on the active input power of the lighting 


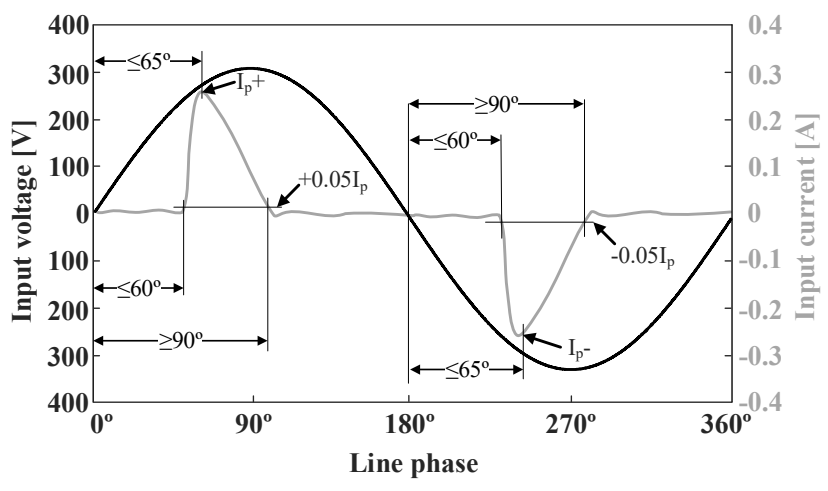

Note: $I_{p}$ represents the higher value of $I_{p}+$ or $I_{p}-$. [18].

Fig.4. Illustration of the relative phase angle and current parameters

equipment. If the power exceeds $25 \mathrm{~W}$ (i.e., luminaires), then the harmonic content of the input current needs to be limited in terms of a certain percentage of the fundamental harmonic (i.e., Class C limits of [18]), taking into account that the third harmonic is also limited by the PF of the input current. However, if that is not the case and the active input power is below or equal to $25 \mathrm{~W}$ (i.e., LED lamps), then the input current needs to either have its harmonic components limited by a set of maximum values per harmonic (i.e., Class D limits of [18]), or fulfil a set of conditions. This conditions shape the waveform requiring that the third and the fifth harmonic component of the current shall not exceed $86 \%$ and $61 \%$ of the fundamental current, respectively. In the latter, these conditions need to be achieved while fulfilling that the input current reaches $5 \%$ of its crest value at $60^{\circ}$ or before, that its crest is reached at $65^{\circ}$ or before. In addition, its value is required not to fall below $5 \%$ of its crest value before reaching $90^{\circ}$, referred to any zero cross of the input voltage, as can be seen in Fig. 4. The ac-dc LED drivers that comply with this condition will be considered as medium PF.

It can be concluded, taking into account the preceding requisites, that the regulation is laxer for lighting equipment below $25 \mathrm{~W}$. In that sense, this broadens the study of topologies that can distort the input current to a certain extent while still achieving a low cost solution. However, this is not the case for equipment exceeding $25 \mathrm{~W}$, as Class C limits are considered the most restrictive of the four classes detailed in IEC 61000-3-2. This implies that the current shape needs to be sinusoidal and aligned with that of the input voltage, which normally means achieving unity PF, thus those ac-dc LED drivers that need to comply with this regulation will be classified into the high PF subcategory. This characteristic limits ac-dc LED drivers of more than $25 \mathrm{~W}$ to those topologies that can achieve Power Factor Correction (PFC), as will be seen in Section III, and understanding PFC as the ability of demanding a sinusoidal current in phase with the input voltage, thus achieving unity PF.

\section{C. $\quad$ Flicker metrics}

The flicker phenomenon can be defined in terms of any lighting equipment as a rapid repetitive change in luminance [19]. Particularly, in the case of LEDs, it occurs due to the fast response to current variations. Precisely, the harmonic content of the current flowing across the LEDs translates into a light output modulated by those components. However, not all frequency components are equally harmful for humans, and only those below $3 \mathrm{kHz}$ can be considered as such. In fact, whether the low frequency modulation is visible or invisible, it can trigger headaches, migraines, fatigue, epilepsy or any other neurological response [20].

Reducing flicker harmful effects has become increasingly important for ac-dc LED drivers, since conceptually double the mains frequency can easily appear at the current across the LEDs. For instance, without a proper flicker regulation, the output capacitor of the ac-dc LED driver that decouples the ac component of the current across the LEDs and thus controls the admissible ripple of the current, can be overestimated causing the life expectancy of the ac-dc LED driver to decrease or underestimated causing flicker to appear. Therefore, the flicker recommendation truly sets the limits on the allowed amplitude of the luminance and as such, the size of the output capacitance. For that matter, two simple metrics were defined in order to give a measure of flicker [20]:

- Flicker index [21] is defined as the area above the line of average luminance (i.e., $\mathrm{L}_{\mathrm{dc}}$ ) divided by the total area of the light output curve during a cycle, refer to Fig. 5,

$$
\text { Flicker Index }=\frac{\text { Area }_{1}}{\text { Area }_{1}+\text { Area }_{2}} .
$$

This metric has been developed for fluorescent lamps and has the advantage of taking into account the waveform shape.

- Percent flicker [21], also known as Modulation (\%), which is the preferred expression due to its relationship with the ripple of the luminance waveform, can be defined as,

$$
\operatorname{Mod} .(\%)=\frac{\mathrm{L}_{\max }-\mathrm{L}_{\min }}{\mathrm{L}_{\max }+\mathrm{L}_{\min }} \cdot 100,
$$

where $\mathrm{L}_{\max }$ and $\mathrm{L}_{\min }$ define the maximum and minimum luminance that the LEDs are producing, respectively.

The issue with the aforementioned definitions is their independence from the frequency of the signal and the lack of a relationship with human perception. In the last decade, efforts toward a set of recommendations have been made due to the lack of association between flicker and frequency in

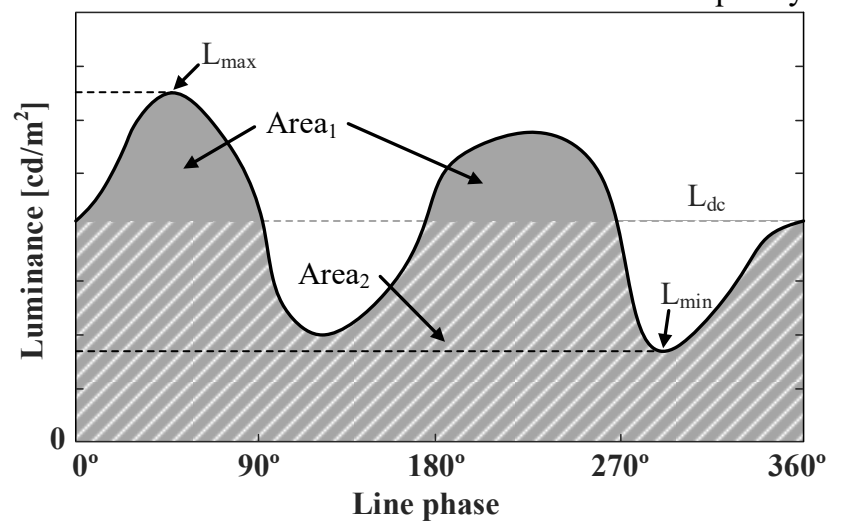

Fig.5. Illustration of the luminance over the line phase to exemplify the estimation of flicker index and Mod. (\%). 
Table II. Recommended practices, in accordance to IEEE Std. 1789-2015 [23].

\begin{tabular}{|c|c|}
\hline Practice 1 & $\begin{array}{l}\text { If it is desired to limit the possible adverse biological effects of flicker, then flicker Mod. (\%) should } \\
\text { satisfy the following goals: } \\
\text { - Below } 90 \mathrm{~Hz} \text {, Mod. }(\%) \text { is less than } 0.025 \times \text { frequency. } \\
\text { - Between } 90 \mathrm{~Hz} \text { and } 1250 \mathrm{~Hz} \text {, Mod. }(\%) \text { is below } 0.08 \times \text { frequency. } \\
\text { - Above } 1250 \mathrm{~Hz} \text {, there is no restriction on Mod. }(\%) \text {. }\end{array}$ \\
\hline Practice 2 & $\begin{array}{l}\text { If it is desired to operate within the recommended NOEL of flicker, then flicker Mod. (\%) should be } \\
\text { reduced by } 2.5 \text { times below the limited biological effect level given in Recommended Practice } 1 \text { : } \\
\text { - Below } 90 \mathrm{~Hz} \text {, Mod. (\%) is less than } 0.01 \times \text { frequency. } \\
\text { - Between } 90 \mathrm{~Hz} \text { and } 3000 \mathrm{~Hz} \text {, Mod. }(\%) \text { is below } 0.0333 \times \text { frequency. } \\
\text { - Above } 3000 \mathrm{~Hz} \text {, there is no restriction on Mod. }(\%) \text {. }\end{array}$ \\
\hline Practice 3 & $\begin{array}{l}\text { For any lighting source, under all operating scenarios, flicker Mod. (\%) shall satisfy the following goal: } \\
\text { - Below } 90 \mathrm{~Hz} \text {, Mod. (\%) is less than 5\%. }\end{array}$ \\
\hline
\end{tabular}

previous literature. Actually, the requirements in terms of flicker should not be the same for frequencies below $90 \mathrm{~Hz}$ than for those that are higher, since human eyes are more sensitive to those lower frequencies [22].

Nowadays, there is still no such thing as a flicker regulation, but a several sets of complex flicker metrics. On that note, one of the first proposal was done by the IEC 610004-15:2012 [24]. This regulation defines a set of specifications that a flickermeter needs to meet. The main problem with this definition is that the allowed fluctuations are not limited in an adequate frequency range, particularly going from 0.5 to $40 \mathrm{~Hz}$. The latter is of utter importance considering how sensitive humans are to frequencies up to $90 \mathrm{~Hz}$.

In 2015, the IEEE standard 1789-2015 defined a recommendation of practices [23]. These practices are summarized in Table 2 and take into account the frequency of the luminance up to $3 \mathrm{kHz}$. It should be noted that out of the three practice detailed, Practice 2 is the most restrictive one, ensuring No Observable Effect Level (NOEL). Nonetheless, the designer needs to typically aim to comply with Practice 1, as it is restrictive enough to limit hazardous biological effects.

Furthermore, the light output of any lighting equipment connected to an ac power grid can contain several harmonics related to the fundamental frequency of the grid (i.e., $50 \mathrm{~Hz}$ for Europe and $60 \mathrm{~Hz}$ for the US), or even subharmonics below those frequencies due to failures either in the driver or the grid, which can be potentially hazardous. In those cases, the recommendation is clear, stating that all the harmonic components of the measured luminance over a line cycle should lie within the limits stated in the selected practice from Table II.

Two important issues appear with this practice. The first one is that some lighting fixtures, as incandescent light bulbs are deemed not safe in accordance to this practice, The second is the discontinuity that appears close to $90 \mathrm{~Hz}$ which is inconsistent considering this to be a reflection of a biological response. In addition, the IEEE 1789-2015 standard can only be applied to sinusoidal waveforms [25]. Nonetheless, the following of the recommendations truly ensure a flicker-free performance.

Another flicker metric of importance has been proposed by the Alliance for Solid-State Illumination Systems and Technologies (ASSIST) [26]. This metric is based on measuring the light output of a certain light source and performing a series of mathematical operations to yield a metric value that needs to be necessarily below one to ensure a flicker free performance. The first step is acquiring a sampled waveform of the luminance at a recommended sampling rate of 2000 samples/s during 2 seconds. Then, the Fourier Transform is applied to this waveform in order to obtain the amplitude of each of the components that comprise the luminance waveform. These components are used to attain Mod. (\%) at each frequency, which are, then, weighed accordingly with a human eye sensitivity curve. Finally, the weighed components are summed with a quadrature sum to attain the desired metric value [26].

Even though this method is extended to any kind of waveform and not only to sinusoidal waveforms as the IEEE 1789-2015, it weakness lies in not considering the flicker sensitivity in the range between 100 and $200 \mathrm{~Hz}$ [25].

In 2017, the National Electrical Manufacturers Association (NEMA) proposed a criterion to determine the safety of a temporal light artifact [27]. The methodology for low frequencies (i.e., $<80 \mathrm{~Hz}$ ) is based in the IEC 61000-45:2012 (defining the $\mathrm{P}_{\mathrm{st}}$ parameter within) and is completed for high frequencies (i.e., $>80 \mathrm{~Hz}$ ) with the Stroboscopic Visibility Measure (SVM). In fact the SVM is based on the methodology proposed by [28]. The NEMA 77:2017 requires $\mathrm{P}_{\mathrm{st}}$ to be lower than one for both outdoor and indoor applications and only limits SVM for indoor applications at 1.6. This criterion is not as restrictive as the IEEE 1789:2015 but addresses the main problem it had with incandescent lights. The main drawback is that it can only be applied to sinusoidal waveforms. 
The last flicker meter that is going to be discussed is the Compact Flicker Degree (CFD), which essentially works as ASSIST LRC, but in this case taking into account all Fourier frequencies up to $2 \mathrm{kHz}$, thanks to its different human eye sensitivity function, instead of stopping at $100 \mathrm{~Hz}$. Then a metric is generated by summing all the weighted Mod. (\%). In order to achieve a flicker free performance the CFD metric needs to be less than $1 \%$, considering imperceptible those values between $1 \%$ and $12.5 \%$, and acceptable and rarely perceived by humans the range between $12.5 \%$ and $25 \%$ [25]. In addition, this parameter can be used with any light waveform.

Fig. 6 shows a comparison between all the aforementioned flicker metrics in terms of the allowed Mod. (\%) at each frequency. As can be seen Practice 2 of the IEEE 1789-2015 is the most restrictive of all the discussed flicker metrics, considering that even incandescent lamps are considered to have flicker, whereas NEMA 77 can be considered the less restrictive. It should be noted that the IEC 61000-4-5:2012 curve is represented within the NEMA 77 curve from 1 to 80 $\mathrm{Hz}$ as this flicker metric is based on it under that frequency range. However, from that point onward the IEC 61000-45:2012 curve follows the ASSIST LRC curve that does not consider the higher frequencies to cause any harmful effect.

In order to address the presented flaws within each criterion, the International Commission of Illumination (CIE) is currently working in a standard that is able to clearly state and define a flicker regulation [29]. Nonetheless, and considering all these different metrics, the one thing that they do have in common is that they set very specific rules to the admissible fluctuations of the light at certain frequencies, which in the case of LEDs is translated to the admissible ripple of the current. Particularly, for ac-dc LED drivers this ripple is completely reliant on the value of the output capacitance that buffers the pulsating power from the ac mains, meaning that as long as this capacitor is big enough, a flicker-free performance can be guaranteed. The problem present is that in most cases an electrolytic capacitor will be required in order to meet the required current ripple across the LED load. For that matter, the flicker-free condition will determine whether an electrolytic capacitor-less ac-dc LED driver can be achieved for the different solutions that will be discussed in this paper.

It is important to note that depending on the flicker metric or the LEDs used the size of the capacitor will differ, meaning that while some flicker metrics will be able to dispose of the electrolytic capacitor for certain LED strings others will not. For this reason whenever a topology is considered to remove the electrolytic capacitor, this will be evaluating the strictest regulation set by practice 1 of the IEEE 1789-2015.

\section{SINGLE-PHASE AC-DC LED DRIVERS}

Considering that the primary access in homes, streets and offices is single-phase ac, it is required the use of an ac-dc converter in order to drive an LED load (i.e., ac-dc LED driver), to guarantee a flicker free performance. However, several distinctions can be made depending on the LED load

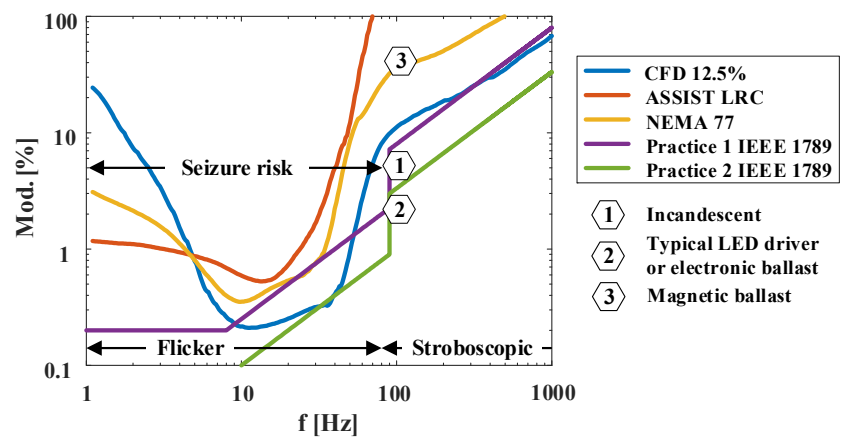

Fig.6. Comparison of different flicker metrics in terms of the allowed Mod. (\%).

to drive. In fact, the regulations (i.e., ENERGY STAR ${ }^{\circledR}$ and IEC 61000-3-2) differentiate between two rules in function of the input power of the LED load. The laxer regulation set for LED lamps (i.e., lighting products of less than $25 \mathrm{~W}$ ) makes possible the usage of simple, and inexpensive passive solutions, whereas LED luminaires (i.e., lighting products of more than $25 \mathrm{~W}$ ) need to comply with the most restrictive set of rules, requiring the use of a PFC solution.

\section{A. Passive}

Passive solutions, normally applied to retrofit/replacement lamps of less than $25 \mathrm{~W}$, require the least components of all the solutions that are going to be discussed along this section. In this case, the input current of the driver is not required to be sinusoidal in accordance to Class D regulation or to the graphic limits set by Fig. 4, allowing some degree of distortion to happen in the input current. In contrast, some benefits are traded-off:

- the ability to control the current, unless a trimmer that will further distort the current is used [30]. The addition of a trimmer may also cause flicker to appear under dimming conditions.

- the lower lifespan of the lamp, due to the inability to remove the electrolytic capacitor.

- the efficiency, due to the resistive elements introduced to limit the peak current.

The conventional passive solution, depicted in Fig. 7 (a) and (b), is based on using a capacitor-input filter to generate a dc voltage in order to feed the LED load at either high voltage [31] or low voltage [32]. It should be noted that the current across the low voltage solution is phase shifted $90^{\circ}$ with respect to the input voltage allowing the conducting angle to increase. The current across the LED load for both passive solutions is not controllable and resistor $R_{B}$ needs to be included to limit the peak current. The inclusion of this resistive element hinders the efficiency of the solution. Another possibility to drive LEDs passively is depicted in Fig. 7 (c); this solution is based on using the LED load to rectify the input voltage, thus using a string for the positive half line cycle and the other one for the negative half line cycle. This 


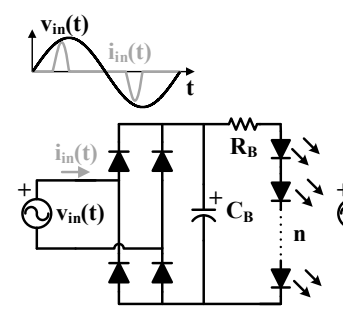

(a)

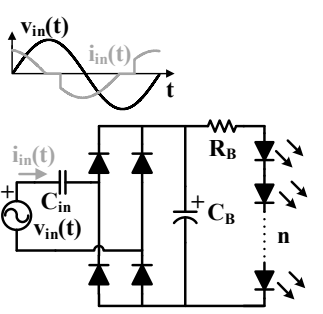

(b)

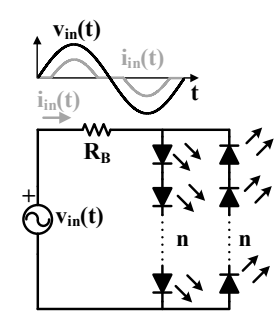

(c)

Fig. 7. Typical passive solutions to drive LEDs from ac single-phase power grids. (a) Capacitor-input filter [31]. (b) Voltage-step-down capacitorinput filter [32]. (c) Conventional AC-LED driver [36].

technique is referred in literature as Low Frequency (LF) ACLED driving [33]-[38], and presents two important drawbacks: the first is the low frequency flicker due to the driving of the LEDs with a sinusoidal current, and the second is that the amount of LEDs used is duplicated when compared to the capacitor-input filter solution. In contrast, the efficiency is increased and the lifetime of the driver is prolonged, as the electrolytic capacitor is not required considering the ac driving does not have an impact on the lifespan of the LEDs in accordance to [39]. It should be noted that there have been some proposals to reduce the amount of LEDs used in this solution; however, the number is always greater than the conventional solution [36]. Furthermore, the limiting resistance is still required. Other solutions have replaced the limiting resistance by a capacitor to passively balance several LED strings [40], method that was widely used in cold cathode fluorescent lamps, or even inductors in series with the string [41]. The latter, would increases the size of the ac-dc LED driver significantly due to the low frequency inductors required, and its use is mainly recommended for high frequency AC-LED driving.

In order to solve some of the aforementioned problems, some authors have proposed using a valley-fill circuit in conjunction with an output inductance [42]-[44]. This configuration reduces the harmonic content of the input current and eliminates the electrolytic capacitor, thus improving the lifespan of the ac-dc LED driver, see Fig. 8 (a). In contrast, other authors have included complex input filters to improve the THD and PF, improving the scope of the passive solutions to not only drive low power luminaires, but not eliminating the bulk capacitor, see Fig. 8 (b) [45]. However, the trade-off that comes with these kind of solutions is the increased cost due to the amount of components and the inclusion of low frequency bulky inductors that will increase the size and weight.

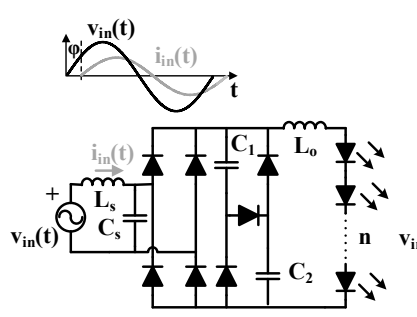

(a)

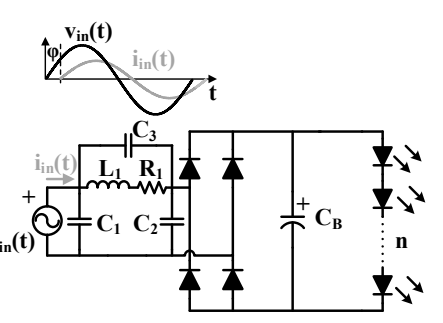

(b)
Fig. 8. State of the art passive solutions to drive LEDs from ac singlephase power grids. (a) Valley-fill circuit based [42]-[44]. (b) Filter based [45].

\section{B. Active}

Active single-phase ac-dc solutions are defined by one or various active components that are controlled in order to shape the input current while keeping a dc output voltage/current. The analysis carried out is focused on switch mode power supplies considering that linear regulators are extremely inefficient for this purpose [65].

One way to classify active ac-dc LED drivers, following Fig. 3 , depends on the amount of power stages included in the acdc LED driver. In that sense, an ac-dc LED driver comprised by a single power stage would fall into the single stage category, whereas a driver with two or more cascaded power stages will fall into the multi-stage category. Those ac-dc LED drivers that fall in between, based on the integration of two stages would be classified into integrated single-stages. Moreover, the addition of a power stage that does not process all the power will be classified as a multi-stage solution, even if they are normally referred as quasi- or pseudo-single-stages [64], [85], [88], [89], [91]-[105], [119], [121]-[133], [140][155]. In this classification, an extra category is added in order to include those drivers comprised of more than one power stage connected in any of the modular configurations: Input Series Output Parallel (ISOP), Input Parallel Output Series (IPOS), Input Series Output Series (ISOS) or Input Parallel Output Parallel (IPOP). Furthermore, within the previous categories, some design conditions should be distinguished. Firstly, the inclusion of galvanic isolation or not, which is a recommended practice to isolate the normally safe voltages withstood by the LED load from the grid; secondly, the input power of the luminaire and its implication over the allowed PF or input current shape depending on the regulation; and lastly, the removal of the electrolytic capacitor. Accordingly, different solutions can be yielded when conceiving these distinctions.

\section{1) Single-stage solutions}

Active single-stage ac-dc solutions are massively used in ac-dc LED drivers due to their low cost and simplicity over the conventional two stage solution. In contrast, some limitations appear on the requirements set at the start of this section: the electrolytic capacitor cannot always be removed, the efficiency tends to be low (i.e., $<90 \%$ ), a universal input solution can be difficult to be achieved, and the dc voltage 
conversion ratio can be required to be rather high. In fact, one of the biggest issues is that a trade-off between the benefits needs to be made, as an example; a single-stage ac-dc LED driver may be unable to provide both dimming and universal input voltage range. Therefore, taking into account the previous facts, single-stage solutions can be further classified in terms of their input power into two different categories: LED lamps and LED luminaires in accordance to IEC 610003-2 input power distinction. The less than $25 \mathrm{~W}$ category engulfs both low PF and medium PF categories introduced in Fig. 3. As reminder, the low PF subcategory is defined in accordance to ENERGY STAR ${ }^{\circledR}$ for those ac-dc LED drivers of less than $5 \mathrm{~W}$ of input power that also require a $\mathrm{PF}$ of more than 0.5. The medium PF subcategory is defined for those LED drivers of less than $25 \mathrm{~W}$ of input power that need to comply with the Class D of the IEC 61000-3-2. The high PF subcategory is lastly defined for those ac-dc LED drivers of more than $25 \mathrm{~W}$ that need to meet the requirements of Class $\mathrm{C}$ of the IEC 61000-3-2 regulation, which is an almost sinusoidal input current in phase with its input voltage.

The simplest approach to design a single stage ac-dc LED driver for LED lamps can be found in Fig. 9 (a) based on having a capacitive input filter followed by a dc-dc converter. The capacitive input filter yields a constant voltage at the input of the dc-dc converter. The dc-dc converter then controls the current fed to the LED string. The issues with this approach are its low PF and the inability to remove the electrolytic capacitor. However, some authors have been able to remove the electrolytic capacitor while achieving a flicker-free performance and complying with IEC 61000-3-2 in terms of the input current waveform, see Fig. 4, by means of an asymmetrical half bridge flyback converter [46].

The other approach to design a single stage ac-dc LED driver for both input power ranges is depicted in Fig. 9 (b) using a dc-dc converter operating as a Loss Free Resistor (LFR). This approach is able to attain a sinusoidal input current waveform in phase with its input voltage with a correct selection of the PFC converter and its control. The main drawback is the inability to remove the electrolytic capacitor while guaranteeing a flicker free performance due to the power pulsation of the mains.

The removal of the electrolytic capacitor is normally performed with a second stage that compensates the low frequency ripple on the output voltage in order to attain an acdc LED driver with a lifetime comparable to that of the LEDs. However, achieving this performance in a single-stage ac-dc converter is not an easy task, and more components are required. In that sense, some authors propose the use of valleyfill circuits [47]-[49] as what was shown in Fig. 8 (a) for passive solutions. The proposal is able to remove the electrolytic capacitor at the cost of having an increased amount of passive components and a low efficiency.

Another alternative to remove the electrolytic capacitor, in single-stage ac-dc converters, is distorting the input current. Some authors have proposed the injection of the third, fifth or even seventh harmonics attempting to reduce the heavy pulsation of the input power if a pure sinusoidal current is

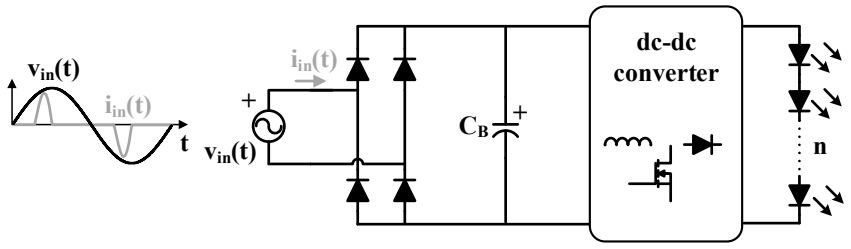

(a)

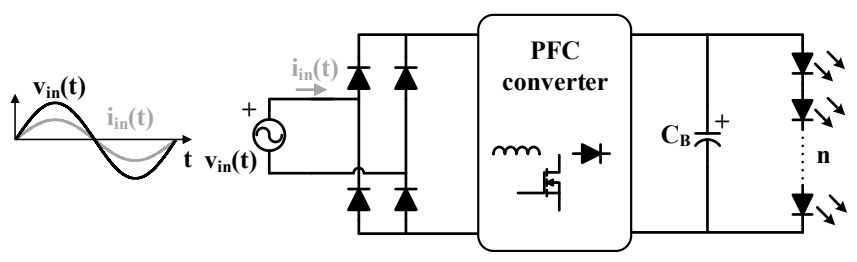

(b)

Fig. 9. (a) Single stage based on a capacitive input filter for low and medium PF. (b) Single stage based on a single-stage LFR for high PF.

demanded [50]-[53]. The analysis shows for ac-dc LED drivers that requirements with ENERGY STAR ${ }^{\circledR}$ can be met in terms of PF. However, ensuring compliance with Class $\mathrm{C}$ IEC 61000-3-2 still requires the use of an electrolytic capacitor. Hence, the distortion of the input current is particularly interesting for ac-dc LED drivers dedicated to retrofit LED lamps (i.e., $<25 \mathrm{~W}$ ). This opens a handful of simple active solutions, even if the electrolytic capacitor is not removed considering the cost is the main concern for this application, as are: the use of Active Input Current Shapers (AICS), or buck converter and its multiple variants, normally neglected for PFC.

Several solutions for retrofit LED lamps have been proposed based on using non-isolated buck converters either as a single-stage or quasi-single-stage [54]-[59], [129], see Fig. 10 (a), isolated converters from the buck family [46], [60], using an LFR as the limiting resistor rendering an AICS [84], as depicted in Fig. 10 (b). The converters from the buck family show better efficiencies than the ones from the buckboost family, with the limitation of the conducting angle that is only able to comply with the regulation set for LED lamps.

Before continuing on discussing the different topologies used in ac-dc LED drivers, it is important to define the LFR concept. An LFR is a dc-dc converter behaving as a resistor at its input and as a power source at its output by means of control [61], [62]. The resistive value of the LFR (i.e., $\mathrm{R}_{\mathrm{LFR}}$ ) depends on a certain control variable, $\mathrm{v}_{\mathrm{c}}$. This is a well-known concept in the ac-dc PFC field, where a sinusoidal current in phase with the input voltage of the converter is desired [63].

As regards the solution based on using an LFR (i.e., Fig. 10 (b)) to limit the current on the LEDs, it should be noted that it is able to achieve a high step-down ration between input and output voltage with a simple approach requiring an isolated converter working as an LFR. This solution slightly distorts the input current demanded rendering an AICS, whose main drawback is its inability to remove the electrolytic capacitor [84]. 
That being said, the simplest and most massively used converter in single-stage ac-dc LED drivers for both power ranges, with its multiple variants, is the flyback converter in accordance to previous reviews on the topic [65]-[68]. A flyback converter, see Fig. 10 (c), is a converter from the buck-boost family that includes galvanic isolation thanks to its coupled inductor [69]. By being a member of the buckboost family, it is able to achieve unity PF and PFC naturally by working in Discontinuous Conduction Mode (DCM), which simplifies its control. In contrast, the converter is unable to remove the electrolytic capacitor while ensuring a flicker-free performance, and it suffers from low efficiencies because of being a converter from the buck-boost family that requires a passive snubber, used in low cost solutions, to protect the main switch from voltage spikes caused by the leakage inductance of the couple inductor [70]-[86].

Delving into single-stage ac-dc LED drivers for luminaires (i.e., $>25 \mathrm{~W}$ ) most of the topologies are shared topologies with the retrofit ones, as long as they demand a sinusoidal current [72]. In the case of luminaires, the preferred solutions are focused around the buck-boost and the boost converter family. The first is able to provide the LED with lower voltages while keeping a sinusoidal current. Among the non-isolated buck-boost family solutions: the buck-boost [92]-[102], the Ćuk [107]-[110], the SEPIC [100]-[105], [111]-[113] and the Zeta [114] converters can be found. The last three are normally avoided in low cost applications due to their increased number of components [115], [116]. In fact, their isolated variants are barely used in ac-dc LED drivers due to the versatility of the flyback converter and the

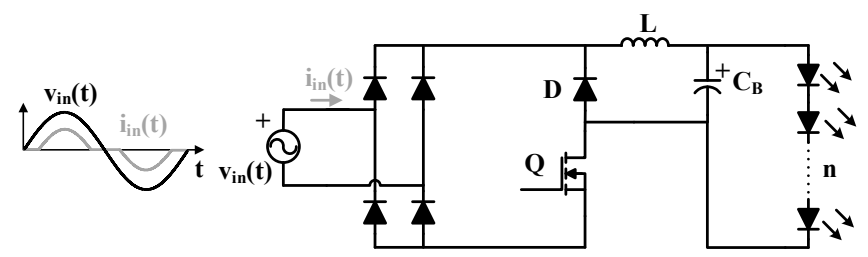

(a)

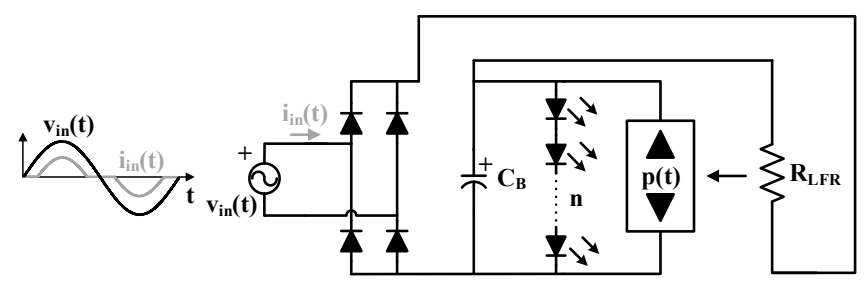

(b)

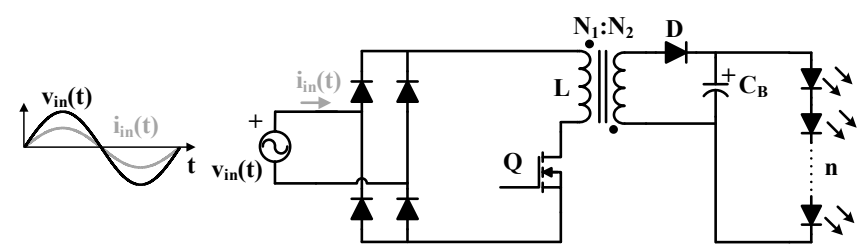

(c)

Fig. 10. Some examples of LED drivers for retrofit lamps. (a) Buck converter [54]-[59], [129]. (b) Equivalent circuit of the LFR based AICS [84]. (c) PFC flyback converter [70]-[86]. fact that their integrated stages with an isolated or non-isolated dc-dc converter tend to be more efficient, able to remove the electrolytic capacitor and have a lower component count [67].

The boost converter can also be used in single-stage ac-dc LED drivers for luminaires. However, the necessity to work with higher voltages has made the use of this converter situational due to the amount of LEDs required in series for the LED load, which is not a recommended practice in terms of reliability. Nevertheless, the advances in LED technology have made possible the use of an ac-dc single-stage boost converter to drive high voltage LEDs [117], [118]. Otherwise, a boost integrated with a step-down dc-dc converter can be used to drive LEDs, being either a conventional [87]-[93], [177] or a bridgeless PFC boost [94]-[97]. The latter has the same operation as a conventional boost, but the low frequency diode bridge is removed in order to achieve an improvement in its efficiency.

The isolated variations of the boost converter family, also referred as current-fed isolated converters, are rarely used in PFC due to the several issues they present, such as, complex transformer design, the need for demagnetization path for their main inductance or inductances, or complementary signals in comparison to the traditional controllers. Furthermore, due to the lack of commercially available analog controllers for the driving of current-fed topologies, the control is normally implemented digitally, which for this particular application can be considered a drawback as its cost and complexity increases.

It is because of the aforementioned issues that their potentially higher efficiency is hindered achieving a similar level to that of the buck-boost family isolated converters [134]. Nonetheless, some works of single-stage ac-dc currentfed isolated converters have been proposed in literature, such as, a current-fed push-pull [135], see Fig. 11, a dual inductor current-fed push-pull [136], or a current-fed full-bridge [137]. In the previous literature, the use of these topologies to implement ac-dc LED drivers can be found, particularly a push-pull converter in [138] and a dual inductor current-fed push-pull in [136]. The first proposal does not address any of the aforementioned issues, achieving a very low efficiency while suffering at the same time from high voltage stress on the main switches. In contrast, the dual inductor current-fed push-pull reduces the stress on the main switches, achieves a high efficiency (i.e., $>90 \%$ ) and reduces the input current ripple thanks to the interleaving that occurs between is two input inductances. However, it is unable to remove the

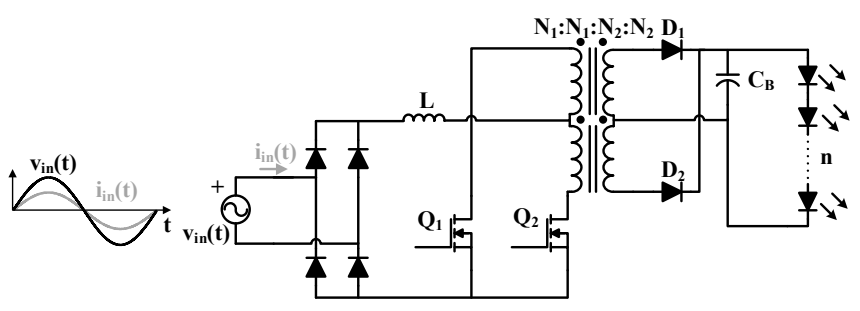

Fig. 11. Example of isolated boost based ac-dc LED drivers for luminaires based on a current-fed push-pull [138]. 
electrolytic capacitor if a flicker-free solution wants to be achieved.

As regards the dynamic response of single-stage ac-dc LED drivers, it is normally slow due to the low bandwidth output current loop required to filter the low frequency harmonics from the mains that appear on the output current. This is not the case for most solutions that integrate a twostage ac-dc LED driver or in the upcoming multi-stage ac-dc LED drivers, as the second stage can provide a higher bandwidth. Nonetheless, the dynamic response is unimportant for LEDs as they are considered a slow load for illumination products, as long as the low frequency output ripple is cancelled [8]. In addition, the control of the proposed solution follows a traditional approach that can be typically implemented with a commercial analog IC, which simplifies its control and reduces the cost of the LED driver.

\section{2) Integrated single-stage solutions}

One of the most used methods to achieve a single-stage that is able to remove the electrolytic capacitor without incurring into flicker falls into what can be considered a quasisingle-stage. This method combines typically well-known topologies of the first and the second stages under shared switches [87]-[105], [119]-[133] based on the concept proposed in [106], see Fig. 12.

The integrated single-stages bases its operation on allowing a certain ripple on $\mathrm{C}_{\mathrm{B}}$. However, this ripple is cancelled at the output of the converter with the help of a control loop included in the dc-dc converter stage that is able to correct the low frequency variations. In particular, this case follows the same principle used in two-stage solutions that will be discussed later on in Section III.B.3). Then, it is not unexpected that the presented topologies are based on the most popular multi-stage solutions. However, the rendered topologies are not as efficient as the two-stage solutions that they come from, due to stress happening on the switches as a consequence of sharing operation for both stages, and in most cases they still perform a double power conversion. In the end, it is a matter of making a trade-off for a more cost effective solution with a higher power density, and without a flicker and an electrolytic capacitor.

It should be noted that within this category falls the traditional AICS approach, its operation is based on integrating an AICS with a dc-dc converter. This solution is

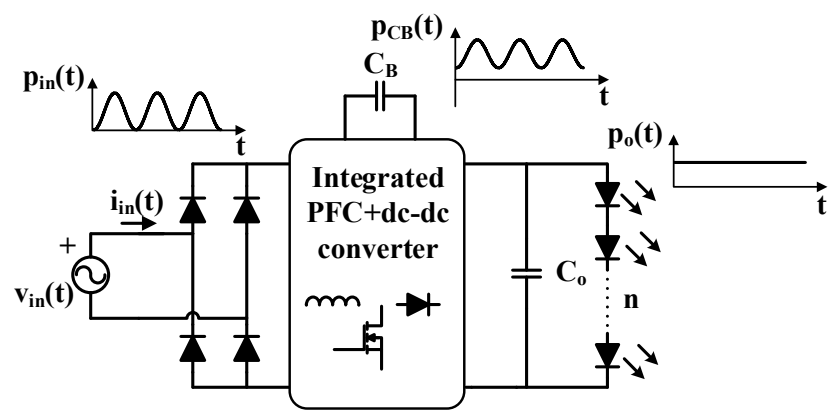

Fig. 12. Integration of a two-stage into a single-stage with common active components [87]-[105], [119]-[133]. able to remove the electrolytic capacitor allowing a certain ripple to appear on the intermediate bus capacitor (i.e., $\mathrm{C}_{\mathrm{B}}$ ), causing some distortion to appear on the input current. The drawbacks of this solution are its low efficiency, and its narrow input voltage range operation due to the difficulties to limit the voltage on $\mathrm{C}_{\mathrm{B}}$ while keeping a PF below 0.7 and an efficiency higher than $80 \%$ [64], [85]. Hence, its use for medium PF ac-dc LED drivers.

\section{3) Multi-stage solutions}

Conventionally, in PFC, two-stage solutions have been used to drive dc loads, see Fig. 13 (a) [63]. The first stage is dedicated exclusively to perform PFC by using topologies that could achieve unity PF and provide the second stage with an almost constant voltage with a certain ripple. Consequently, the second stage is dedicated to ensure an adequate voltage or current level on the LED load. In addition, it is required to correct the low frequency ripple that appears due to the lower capacitive value of $C_{B}$ to achieve the removal of the electrolytic capacitor, which causes the power to slightly pulsate at the input of the dc-dc converter $\left(p_{\text {indc }}(t)\right)$. It should be noted that for the power range in which the multi-stage solution is used (i.e., the driving of LED luminaires), the inclusion of galvanic isolation is recommended and tends to be mandatory. In fact, galvanic isolation can be included in either the first or the second stage.

Although it can be done in the first stage by means of a flyback converter, this implementation suffers from low efficiencies and a bulkier capacitor due to the lower power density of low voltage capacitors in comparison to high voltage ones [156], [157]. Considering this fact, the inclusion of galvanic isolation is normally performed in the second stage. Other authors have proposed using an integrated single-stage (i.e., bridgeless PFC + LLC) as the front-end followed by simple dc-dc converters to regulate the LED strings [158]. This solution has a high component count but is able to ensure good light quality and current sharing while disposing of the electrolytic capacitor and having a high efficiency .

It is commonplace to think that a two-stage solution would be less efficient than the previously presented single stage solutions. The reasons are the increased number of components and the double power conversion. Even so, the two-stage solution overall performance is better in terms of efficiency and reliability, due to the better optimization of its tasks in its two different stages. In addition, it may be able to remove of the electrolytic capacitor [138].

Continuing on the proposals to remove the electrolytic capacitor, the last ones are those that fall into what can be considered quasi-single-stage ac-dc converters but are considered within the multi-stage category due to their addition of an extra stage. The reason for being considered quasi-single stage despite their inclusion of an extra stages comes from the fact that this extra stage does not process all the power as in the fully cascade solution of Fig. 13 (a). Such are the ones that include a bidirectional dc-dc converter in parallel with the LEDs [140]-[146] or the ones based on multi- 
output ripple cancellation [147]-[155]. In the first scenario, see Fig. 13 (c), the bidirectional converter handles the pulsating power (i.e., $\mathrm{p}_{\mathrm{CAF}}(\mathrm{t})$ ) of $\mathrm{C}_{\mathrm{B}}$ consequently diminishing its size. In addition, $\mathrm{C}_{\mathrm{AF}}$ can have a reduced capacitance as its charge and discharge is done more efficiently in comparison to the grid pulsating power, and unlike the two stage solution, the bidirectional converter does not process all the power. It should be noted that the parallel converter with a capacitor can be changed for a series converter with an equivalent inductance; however, the required inductance is much bulkier,

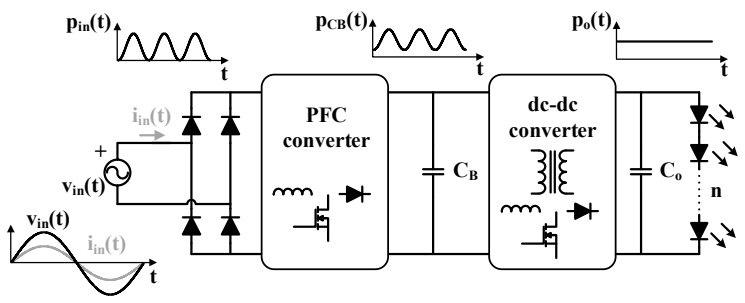

(a)

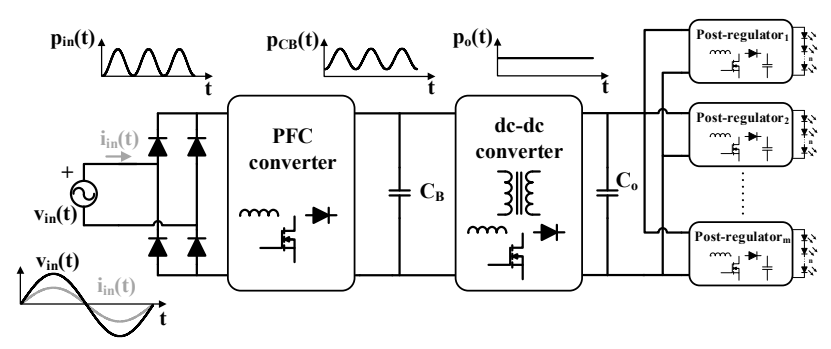

(b)

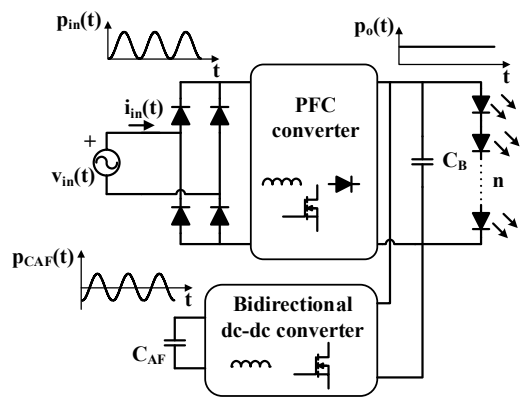

(c)

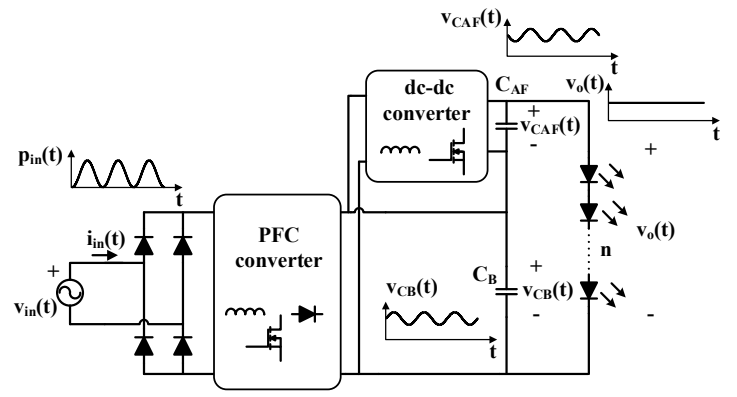

(d)

Fig. 13. Multi-stage solutions for LED drivers. (a) Two-stage solution (Full cascade). (b) Two-stage cascaded with a parallel input post-regulator configuration (Full cascade). (c) Bidirectional dc-dc converter (Active filter) [140]-[146]. (d) Multi-output voltage ripple cancellation (Partial cascade) [147]-[155]. thus it is avoided for ac-dc LED driver. A similar principle is applied in the multi-output voltage ripple cancellation solution in which a certain voltage ripple is allowed on $C_{B}$ in order to reduce its size and value, which is compensated by the dc-dc converter responsible for cancelling it in order to drive the LED load with a dc current, see Fig. 13 (d). For that reason, the output of the dc-dc converter will be a voltage waveform with its phase inverted from the output voltage of the PFC converter. The aforementioned quasi-single-stage solutions present high efficiencies at the cost of a complex control, high component count and low bandwidth on the output current feedback loop. In fact, this complex control would require in some cases the use of digital control, which can also be seen as a drawback, as analog control is preferred for single-stage ac-dc LED drivers.

The aforementioned reasons make the use of two-stage solutions a reality for ac-dc LED drivers. However, as it has been mentioned before, the cost and complexity are the most limiting factors in most applications. Hence, these solutions are normally used for high performance luminaires (i.e., achieving full dimming and flicker free performances) in which reliability and efficiency are of utmost importance. In fact, ac-dc LED drivers occasionally add a cascaded extra stage, referred in previous literature as a post-regulator stage [159], see Fig. 13 (b). The post-regulator is connected directly to the LED string, and the ac-dc LED driver would require, as many post-regulators as there are LED strings in the LED load, considering they are responsible for actively sharing the current between strings to ensure an adequate light output of the luminaire.

Along the summary of single-stage ac-dc LED drivers different solutions to implement the PFC stage have been evaluated. Particularly for multi-stage LED drivers, the most common topology is the PFC boost converter working in either CCM or BCM to achieve unity PF. The latest trends are focused on using its bridgeless variants to achieve higher efficiencies by removing the input diode bridge rectifier [161], [162], making the use of digital control mandatory. Nonetheless, its cost and complexity is justified in multi-stage solutions considering their aim for high reliability and performances, even though traditionally in PFC analog combo controllers have been used [163]. That being said, the focus of this section will be put on the other stages: the isolated dc-dc converter and the post-regulator.

Traditionally the second stage provides fast output voltage response and galvanic isolation. In the case of an LED load, the main characteristic that needs to be fulfilled by the second stage is the cancelling of the low frequency ripple of the PFC converter while achieving a high efficiency in order to remove the electrolytic capacitor. There is a limited spectrum of isolated solutions capable of this performance by means of a fast output feedback loop or a feed-forward input closed-loop, while guaranteeing a flicker free light output. In fact, there are two favored solutions over simpler ones, such as the flyback [164], for this particular application: the LLC resonant converter, that can be found either in its half-bridge, see Fig. 


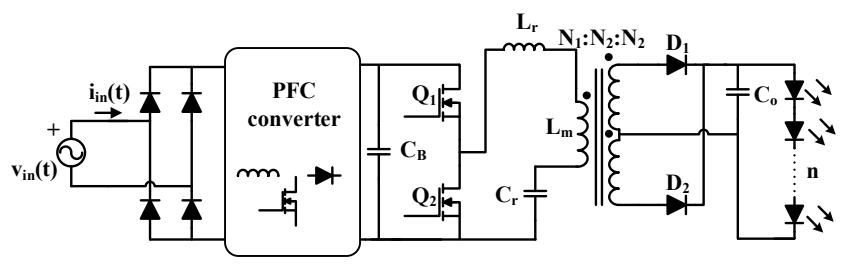

(a)

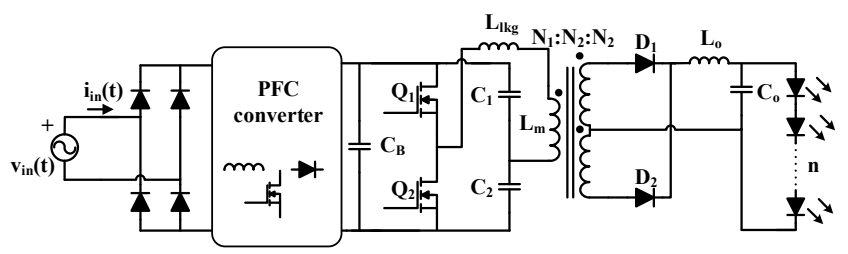

(b)

Fig. 14. Preferred solutions for the dc-dc isolated stage of a multi-stage ac-dc LED driver. (a) Half-bridge resonant LLC [171]-[180]. (b) Asymmetrical Half-Bridge (AHB) [165]-[169].

14 (a), or full-bridge configuration, or the Asymmetrical HalfBridge (AHB), see Fig. 14 (b).

In the case of the AHB, this topology is able to provide high reliability and high efficiency by reaching Zero Voltage Switching (ZVS) in the primary switches [165]-[169]. In addition, the control scheme and the limited output voltage range required for the driving of LEDs allow a small design for its output filter. In fact, the low voltage range makes it possible to implement self-driving techniques when using synchronous rectification in the secondary side of the transformer [166]. On the contrary, the duty cycle range is limited to variations between 0 and 0.5 , the potential bandwidth of its output feedback loop is limited due to the resonance that occurs between the input capacitors and the magnetizing inductance, and the dc gain is not linear. Some authors have proposed different techniques to overcome the bandwidth limitation to cancel the voltage ripple, such as the use of a feed-forward loop [166], [167]. Others have proposed the use of the Zeta AHB (ZAHB), which solves the two main disadvantages of the AHB, as are non-linear gain and the duty limitation [170].

The LLC resonant converter has been widely used for LED driving due to its high efficiency achieved by obtaining soft-switching in its main switches [171]-[180]. However, ZVS is achieved during the turn-on on the primary switches and Zero Current Switching (ZCS) is achieved on the diodes for singular conditions. These conditions limit the operating frequency to lower values than the resonant tank. Hence, when the load reduces the operating frequency will surpass that of the resonant tank, which means that the turn-off losses will increase. Some of the issues related to obtaining soft-switching conditions in this topology are improved for wider power ranges with the help of other resonant tanks [181]-[183].

According to the previous literature, the aforementioned second stages are able to remove the electrolytic capacitor without incurring in flicker, achieve high efficiencies (i.e., > $97 \%$ ) and perform total dimming. However, they are unable to ensure a correct light output in complex LED loads due to the lack of current control on each of the strings, unless a current sharing technique is used. Consequently, some current sharing techniques will be briefly detailed, even though they are unrelated to the achievement of a flicker-free ac-dc LED driver. In fact, for the scope of multi-stage solutions the implemented current sharing method needs to be extremely efficient. This statement discards the linear based regulator and the passive resistor current sharing techniques because of their low efficiencies, reducing the solutions to the use of a post-regulator per string [159], [184]-[189] or a PWM dimmer per string [190], [191]. Another possibility is the integration of the post-regulator with the isolated $\mathrm{dc}-\mathrm{dc}$ converter to reduce the cost and achieve active current sharing by means of multi-output converters [181], [186]. The issues with the integration come from the requirement of several high frequency transformers, which would make the ac-dc LED driver bulkier, and require a complex control to ensure the active current sharing. For this particular application, the buck converter is the preferred solution.

Among the newer trends that could be found in literature to reduce the cost of the second stage or the post-regulator is the driving of LEDs with high frequency pulsed current, also referred in literature as High Frequency (HF) AC-LED. Unlike the Low Frequency (LF) AC-LED described within the passive solutions, the HF AC-LED does not incur in flicker due to the high frequency used. In fact, the difference with a PWM dimming pulsed current is using the switching frequency output current of a dc-dc converter by removing the output filter responsible for obtaining a dc current. This method has been applied to isolated dc-dc converters driving LEDs with a HF sinusoidal waveform [182], [192], [193], a flyback working in DCM with pulsed current driving the LED load with triangular waveform [194], [195], a self-oscillating driving the LEDs with a quasi-sinusoidal waveform [196] and conventional dc-dc converters where the LED is used as the rectifier diode of the converter [197]. Only the authors of the last work had empirically demonstrated the impact of pulsed current driving of LEDs on their lifetime, since they incur in some of the above cases in extremely high current peaks to achieve an adequate dc current level. Moreover, some of them require the duplication of the LED strings [182], [192], [193] not justifying the cost reduction, as the switching output current of the isolated dc-dc converter is required to be rectified.

\section{4) Modular solutions}

Modular solutions are rarely used on ac-dc LED drivers due to the increased amount of components and complexity, potentially reducing the reliability of the driver. Nevertheless, some authors have studied solutions based on stacking several converters in series connected to the ac grid [139], see Fig. 15 (a). This technique allows the use of cheaper and more efficient semiconductors due to the reduction of voltage and current withstood by them, but the overall power density is reduced due to the size limitation of the control stage, 


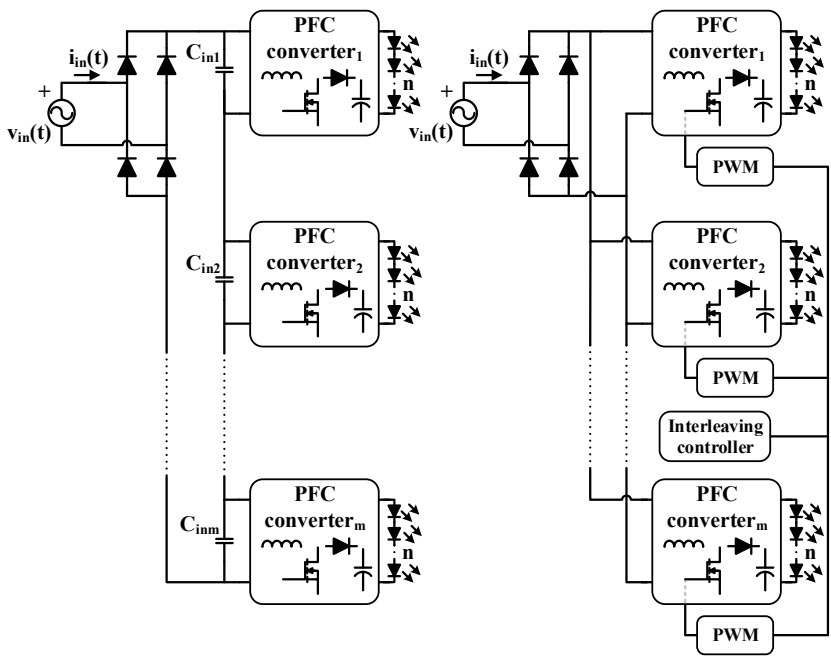

(a)

(b)

Fig. 15. Modular solutions for LED drivers. (a) Input-series [139]. (b) Input-parallel with interleaving [198]-[201].

requiring another feedback loop to control the power demanded by each module. Furthermore, it is able to reduce the size of the output capacitor by stacking several capacitors; however, the removal of the electrolytic capacitor is not naturally achieved.

The other solution, which is well-known in PFC, can be implemented with an input-parallel connection. The idea behind this solution is connecting several PFC converters in parallel at its input. The PWM signal controlling each module is phase shifted in such a manner that the sum of the input currents of each module reduces the high frequency ripple of the current of the ac-dc LED driver [86], [198]-[201], or reshaping the input current achieve a higher PF [202]. In addition, the LED load can also be independent for each module, see Fig. 15 (b). In fact, the more converters there are, the lower the overall current ripple is. This method is referred in literature as interleaving and can be achieved both in open or closed loop with any ac-dc or $\mathrm{dc}-\mathrm{dc}$ converter. Consequently, it is used with the ones that present significant input current ripples in order to reduce it, as those working in DCM or BCM [203], [204]. The main reason for using this technique is the reduction in size of the EMI filter, which grows larger with the input current ripple, affecting both the size and weight of the LED driver [205]. It should be noted that this technique does not impact the removal of the electrolytic capacitor and that the reduction of the EMI filter needs to consider the increased amount of components, as well as, the increase in size and control complexity of a modular solution.

Finally, Table III has been included to comprehensively summarize the most important facts among the discussed solutions for ac-dc LED drivers using generic topologies without delving into specific solutions. In addition several parameters of interest extracted directly from the analyzed references have been added, as are efficiency, PF and THD. In the case of the efficiency the solutions that have achieved the maximum and minimums efficiences are listed, as well as the average efficiency of all the analyzed solutions. As regards design parameters, such as, the ability to operate in univeral voltage input range, the kind of controller used and the ability to perform dimming, the solutions that have these benefits have been listed. It is important to note that as has been previously mentioned the ability for an ac-dc LED driver to comply with the flicker regulation will depend on whether it includes an output capacitor sufficiently large. For that matter, the flicker-free condition column summarizes which solutions are able to eliminate the electrolytic capacitor while keeping a flicker free performance. In fact, those solutions that achieve such feat are listed in their respective category.

\section{THREE-PHASE AC-DC LED DRIVERS}

Along this work, it has been seen that the removal of the electrolytic capacitor is crucial to increase the lifetime of the ac-dc LED driver for it to be comparable to that of the LEDs. The reason behind its use is the pulsating power of the ac grid which would result in a flicker effect on the light output of the LED load, which is both annoying and hazardous for human beings. This is not the case for a balanced three-phase ac power grid and all the required extra stages to remove said component can be disposed of. As outstanding as this is, there are two important limitations preventing three-phase ac-dc LED drivers from being massively used.

Firstly, the lack of voltage standardization. Unlike singlephase power grids, in which the voltage is limited between 80 $\mathrm{V}$ and $270 \mathrm{~V}$, three-phase ac power grids show a wider range depending on the country and power of the grid. For low voltage three-phase ac power grids, the rms line-neutral voltage is nominally $347 \mathrm{~V}$ in Canada, $480 \mathrm{~V}$ in the US [206] or $230 \mathrm{~V}$ in the European Union with the exception of the UK with $240 \mathrm{~V}$. Although the proposal of a universal three-phase ac-dc LED driver seems complex and inefficient, it is not such a limiting factor to use regionally designed LED drivers, when the improvement in cost and simplicity is justified. In fact, considering the scope of power for medium to high power luminaires (i.e., $50 \mathrm{~W}$ to $10 \mathrm{~kW}$ ) the mobility requirement of universal PFC solutions can be completely disregarded.

And secondly, three-phase ac power grids are not as readily available as single-phase ones. This fact reduces the applicability of this solution, since household ac-dc LED drivers represent most of the current LED driver market, and wiring three-phase ac power grids to household environments is costly for the benefits obtained. Therefore, three-phase acdc LED drivers are proposed for those places where the threephase ac power grid is accessible, such as, commercial and industrial installations. The application can then be focused on high power luminaires, tunnel lights, stadium spotlights, floodlights, etc. Particularly, for those luminaires of more than $250 \mathrm{~W}$ that require high reliability and efficiency.

These two reasons are key to understand the most common way used nowadays to drive LEDs in three-phase ac power grids. The method is based on using a LF step-down autotransformer connecting it between line and neutral to adjust the voltage to that of a single-stage ac-dc LED driver [207]. This methodology requires access to neutral, limiting 
TABLE III. SUMMARY OF SINGLE-PHASE FLICKER-FREE AC-DC LED DRIVERS

\begin{tabular}{|c|c|c|c|c|c|c|c|c|c|}
\hline & ADVANTAGES & DISADVANTAGES & $\begin{array}{c}\text { EFFICIENCY } \\
\text { (MIN, AVG, } \\
\text { MAX) } \\
(\%)\end{array}$ & $\begin{array}{l}\text { PF } \\
(\%)\end{array}$ & $\begin{array}{l}\text { THD } \\
\text { (\%) }\end{array}$ & $\begin{array}{l}\text { UNIVERSAL } \\
\text { INPUT }\end{array}$ & CONTROL & Dimming & $\begin{array}{c}\text { FLICKER-FREE } \\
\text { CONDITION }\end{array}$ \\
\hline $\begin{array}{l}\text { Passive } \\
\text { [33]-[38], [40]-[45] }\end{array}$ & $\begin{array}{ll}\text { - } & \text { Low component count. } \\
\text { - } & \text { Simplicity. } \\
\text { - } & \text { No control. } \\
& \text { frompliance with Class D IEC 61000-3-2. }\end{array}$ & $\begin{array}{l}\text { Inability to control luminosity, } \\
\text { unless extra circuitry is added. } \\
\text { - } \quad \text { No galvanic isolation. } \\
\text { - } \quad \text { Rated for less than } 10 \mathrm{~W} \\
\text { Extremely difficult to achieve a } \\
\text { universal input voltage range } \\
\text { solution. }\end{array}$ & $\begin{array}{c}80[35], \\
88, \\
96.1[36]\end{array}$ & $90-99$ & $2-30$ & No & $\begin{array}{c}\text { Only for dimming: } \\
\text { - Analog: [33],[34],[37] } \\
\text { - Digital: } \\
\text { [35],[36],[38] }\end{array}$ & $\begin{array}{c}\text { Yes, with } \\
\text { extra circuitry }\end{array}$ & $\begin{array}{l}\text { Require electrolytic } \\
\text { capacitor. }\end{array}$ \\
\hline $\begin{array}{l}\text { Active: } \\
\text { single-stage }-<25 \mathrm{~W} \\
{[46],[51],[52],[54]-[59],} \\
{[76]-[84],[107],[195]}\end{array}$ & $\begin{array}{ll}\text { - } & \text { Low component count. } \\
\text { - } & \text { Simplicity. } \\
\text { Ability to control the light } \\
\text { output. } \\
\text { - Any dc-de converter can } \\
\text { operate in this configuration. } \\
\text { - Compliance with Class D } \\
\text { from the IEC } 61000-3-2 . \\
\text { - Usage of analog controllers } \\
\text { based on commercial ICs. }\end{array}$ & $\begin{array}{l}\text { - } \quad \text { No compliance with Class C } \\
\text { from the IEC 61000-3-2. } \\
\text { No galvanic isolation: [54]-[59], } \\
\text { [83], [84] } \\
\text { Difficult to remove the } \\
\text { electrolytic capacitor without } \\
\text { incurring in flicker. }\end{array}$ & $\begin{array}{c}55[78], \\
84, \\
96[195]\end{array}$ & $70-92$ & $10-30$ & $\begin{array}{c}\text { Yes. } \\
\text { [51], [52], [55], } \\
\text { [56], [76], [77], } \\
{[79],[81],[83],} \\
{[84],[107]}\end{array}$ & $\begin{array}{c}\text { - Analog: [51], [52], } \\
\text { [54]-[59], [76]-[84], } \\
\text { [107], [195] } \\
\text { - Digital: }[46]\end{array}$ & $\begin{array}{c}\text { Yes. } \\
{[56]-[58],} \\
{[74],[76],} \\
{[107],[195]}\end{array}$ & $\begin{array}{l}\text { No electrolytic: } \\
{[59],[76] .}\end{array}$ \\
\hline $\begin{array}{l}\text { Active: } \\
\text { single-stage }->25 \mathrm{~W} \\
{[47]-[50],[53],[60],} \\
{[73]-[75],[77],[108],} \\
{[110]-[114],[136],[138],} \\
{[196]}\end{array}$ & $\begin{array}{ll}\text { - } & \text { Low component count. } \\
\text { - } & \text { Simplicity. } \\
\text { Ability to control the light } \\
\text { - } & \text { output. } \\
\text { - } & \text { Comusoidal input current. } \\
& \text { from the IEC } 61000-3-2 .\end{array}$ & $\begin{array}{l}\text { Difficult to remove the } \\
\text { electrolytic capacitor without } \\
\text { incurring in flicker. } \\
\text { Trade-off between capabilities } \\
\text { (i.e., dimming, universal input, } \\
\text { capacitor-less, etc.) } \\
\text { No galvanic isolation: [53], [64], } \\
\text { [86] }\end{array}$ & $\begin{array}{c}67[60], \\
89, \\
96[53]\end{array}$ & $95-99$ & $<10$ & $\begin{array}{c}\text { Yes. } \\
{[47]-[50],[73]-} \\
{[75],[77],[111],} \\
{[112],[114],} \\
{[136] .[138]}\end{array}$ & $\begin{array}{c}\text {-Analog: [47]-[50], } \\
\text { [53], [60], [73]-[75], } \\
\text { [77], [108], [110], } \\
\text { [111], [113], [114], } \\
\text { [138], [196] } \\
\text {-Digital: [64], [136], } \\
\text { [112] }\end{array}$ & $\begin{array}{c}\text { Yes. } \\
\text { [49], [64], } \\
{[73]-[75],} \\
{[77],[108],} \\
{[110]-[114],} \\
{[136],[138] .}\end{array}$ & $\begin{array}{l}\text { No electrolytic: } \\
{[47],[48] \text {. }}\end{array}$ \\
\hline $\begin{array}{l}\text { Active: } \\
\text { integrated single stage } \\
{[64],[85],[88],[89],} \\
{[91]-[105],[119],} \\
{[121]-[133]}\end{array}$ & $\begin{array}{l}\text { - } \\
\text { obility to control the light } \\
\text { - } \quad \text { Sinusoidal input current. } \\
\text { - Wide input power range. } \\
\text { Typically used for more than } \\
25 \mathrm{~W} . \\
\text { - } \\
\text { - } \\
\text { High power density. } \\
\text { fompliance with Class C } \\
\text { from the IEC 61000-3-2. }\end{array}$ & $\begin{array}{l}\text { - } \quad \text { High stress on the main switches. } \\
\text { - } \quad \text { Difficult to achieve universal } \\
\text { voltage range. } \\
\text { - } \\
\text { Lacks control on the } \\
\text { intermediate bus voltage. } \\
\text { - Trade-off between capabilities } \\
\text { (i.e., dimming, universal input, } \\
\text { capacitor-less, etc.) } \\
\text { No galvanic isolation: } \\
\text { [95], [97], [100], [119], } \\
\text { [123]-[125], [127], [131]-[133] }\end{array}$ & $\begin{array}{c}73[129], \\
88, \\
95[102]\end{array}$ & $93-99$ & $<20$ & $\begin{array}{c}\text { Yes. } \\
\text { [89], [91], [98], } \\
\text { [103], [129] }\end{array}$ & $\begin{array}{c}\text {-Analog: } \\
\text { [64], [85], [88], [89], } \\
\text { [92]-[94], [96], } \\
{[102]-[105],[119],} \\
\text { [121]-[130], [132],[133] } \\
\text {-Digital: } \\
\text { [91], [95], [97], [131] }\end{array}$ & $\begin{array}{c}\text { Yes. } \\
\text { [88], [92], } \\
{[98],[99],} \\
{[101]-[105],} \\
{[121],[123]-} \\
{[125],[127]-} \\
{[132]}\end{array}$ & $\begin{array}{l}\text { No electrolytic: } \\
{[88],[99],[101],[121] \text {, }} \\
{[124],[131],[132]}\end{array}$ \\
\hline
\end{tabular}


Active:

multi-stage - full cascade

[157]-[159], [161],

[163]-[184], [186]-[190],

[192], [193]

\section{Active: \\ multi-stage - partial \\ cascade}

[147]-[155]

\section{Active:}

multi-stage - active filter

[140]-[146]

Modular

[86], [139], [198]-[202]
- Ability to control the light output.

- Sinusoidal input current

- High efficiency

- Reliability.

- Galvanic isolation.

- Universal input voltage range

- Compliance with Class C from the IEC 61000-3-2.

- $\quad$ Ability to control the light output.

- Sinusoidal input current.

- High efficiency.

- Extra stage does not process all the power.

- Ability to control the light output.

- Sinusoidal input current.

- Extra stage does not process all the power.

- Ability to control the light output.

- Sinusoidal input current.

- Extra benefits (lower THD, independent LED loads, etc)

- High efficiency.

- Typically used for more than $100 \mathrm{~W}$.

- Favors the use of digital or analog-digital controls.

- High component count.

86 [159],

92 ,

95 [158],

[169], [183]

99

(10)

10

159], [161],

[163]-[184],

[186]-[190], [192],

[193]

- Input power of more than $25 \mathrm{~W}$

- High component count

- Problematic in case of output short-circuit.

- No galvanic isolation: [147]

- Input power of more than $25 \mathrm{~W}$.

- High component count.

- High control complexity.

- Extra storage element required

- No galvanic isolation: [145].

80 [142],

$90[145]$

85 [155],

91.5

98 [153], [154]

$<15$

Input power of more than $25 \mathrm{~W}$

- High control complexity.

- Very high component count, due to the multiple modules required.

- No galvanic isolation: [139], [201]

], [150]-[155]

\begin{tabular}{|c|c|c|c|}
\hline $\begin{array}{c}91 \text { [198], } \\
92,\end{array}$ & 99 & $<10$ & $\begin{array}{c}\text { Yes. } \\
\text { [198], [202] }\end{array}$ \\
\hline
\end{tabular}

Yes.

[140], [141],

[143], [144]
- Analog:

[157]-[159], [164],

[169], [173], [174]

- Digital:

[163], [165]-[167],

[170], [172],

[175]-[183], [189],

[192], [193]

- Mixed:
[183], [186], [187]

Yes. No electrolytic:

[157]-[159], [157]-[159], [163]

[161], [166], [167], [169],

[163]-[184], [170], [175],

[186]-[190], [177]-[180]

[192], [193]

- Analog: [147]-[155]

Yes.

No electrolytic:

[151], [154] [148]-[150],

- Analog:

[140], [143], [144]

Digital:

Yes.

No electrolytic:

[142], [145], [146]

[140], [146]

[140]-[146]

- Analog:

[86], [198], [199]

- Digital:

[139], [202]

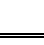


the use of this solution to 4-wire grids. It also reduces the efficiency of the system greatly due to the losses on the autotransformer, which can achieve in the best case $95 \%$ efficiency. Furthermore, the most important aspect is the increase in size and weight that a LF autotransformer does to the whole system [208]. In order to solve the aforementioned issues the use of specific three-phase ac-dc converters to drive LED loads increasing both efficiency and power density, while guaranteeing non-flicker performance have been proposed [209], [210]. This section will focus on the most promising solutions for LED driving based on three-phase acdc considering the lack of previous literature on the topic.

\section{A. Single-stage}

Following the same principle introduced for single-phase ac-dc single-stage solutions, the aim would be to comply with Class C from IEC 61000-3-2, which as a reminder is the most restrictive of the two harmonic injection regulations that a three-phase ac-dc LED driver will need to comply with, being the other Class A from IEC 61000-3-2. Hence, the studied solutions would require sinusoidal input current waveforms in phase with their respective phase voltage. These topologies can be further divided into single-switch and multi-switch categories in accordance to the amount of active switches used. The first ones are the most attractive for LED drivers in terms of cost and reliability. Among these solutions there are two that stand out from the rest, as are the three-phase ac-dc single-switch boost converter, see Fig. 16 (a), and the threephase ac-dc single-switch flyback converter, see Fig. 16 (b).

The three-phase ac-dc single-switch boost converter is able to achieve a quasi-LFR performance in DCM or in pseudo-BCM depending on the gain of converter (M) [211]-[216]. In fact, the higher the converter gain, the lower the THD, requiring at least a gain of 3 and 2.2 to ensure the compliance with Class C from the IEC 61000-3-2 in DCM and pseudo-BCM, respectively. In this particular case, the LED load will be withstanding high voltages (i.e., a minimum of $1 \mathrm{kV}$ for $\mathrm{DCM}$ and $800 \mathrm{~V}$ for pseudo-BCM under the European input voltage standard). Nonetheless, this task can be alleviated with the latest technology of HV LEDs. Moreover, due to the high voltage bus the main switch will incur into higher switching losses and soft-switching will become necessary to achieve an efficient solution. Some authors have proposed the use of passive filtering the input current to achieve lower bus voltages and lower THDs at the cost of increasing weight and size, which is undesirable for an LED driver [215].

In a similar fashion, a dc-dc flyback converter can be connected to a three-phase rectifier, by doing so, galvanic isolation is achieved. However, the LFR performance of the flyback in this configuration will make the input currents of each phase not to be ideally sinusoidal since the conduction angle is $120^{\circ}$, thus not complying with the aforementioned harmonic regulation. In order to solve this issue, an LFR performance needs to be achieved per phase. For that matter,
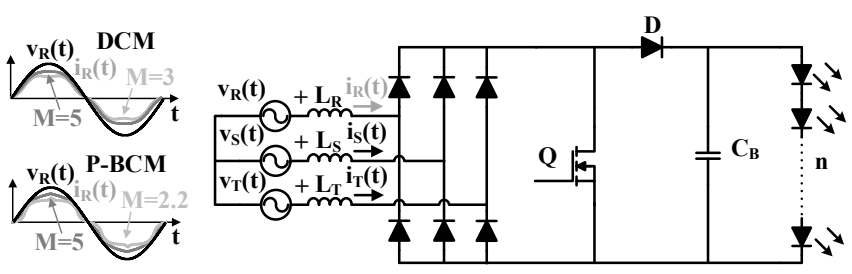

(a)

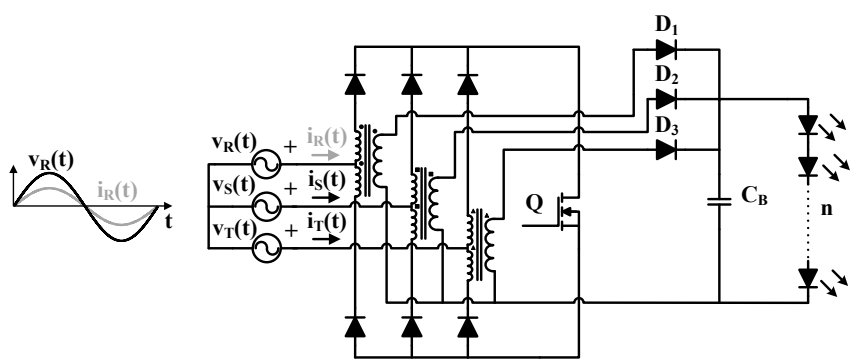

(b)

Fig. 16. Single-switch three-phase ac-dc solutions for LED drivers. (a) Boost converter. (b) Flyback converter [209].

some authors have proposed the three-phase ac-dc singleswitch flyback converter, see Fig. 16 (b), in which a coupled inductor with two input windings is used for each phase. The upper winding conducts during the positive half line cycle of the voltage phase and the lower winding during the negative one [217], [218]. Accordingly, the operation of the driver is equivalent to the use of a flyback per phase achieving the desired operation. However, its PF roughly reaches 0.9 for the higher voltages of the European three-phase ac power grid, its efficiency is well below the desired $90 \%$ for an ac-dc LED driver, the design tolerances of the coupled inductances can severely affect the current ripple on the LED load, and the main switch needs to withstand high voltages and currents [209]. These characteristics make this driver unfitting for luminaires of more than $200 \mathrm{~W}$, which is the desired range of power for LED spotlights. Furthermore, the importance of galvanic isolation introduced for single-phase ac-dc LED drivers to meet the safety requirements, becomes inconsequential for their three-phase counterpart considering the aim for high power luminaires in inaccessible places, which only authorized personnel should have access to.

Taking into account this last statement and in search of more efficient ac-dc LED drivers, multi-switch ac-dc threephase can be considered into this study. Consequently, the simplest topology that can achieve unity PF is the multiswitch boost converter, see Fig. 17 (a) [219]-[222]. In fact, this topology achieves lower voltages on the output bus than the single-switch one previously introduced while keeping a sinusoidal input current. The condition to achieve unity PF requires the output voltage to be greater than the output dc voltage attained by the six diode rectifier bridge formed by the parasitic diodes of each MOSFET. It should be noted that the control is more complex that single-switch solutions and that its bidirectionality is not leveraged for LED applications.

Continuing the analysis, some authors have tackled the design of three-phase multi-switch ac-dc LED drivers by 


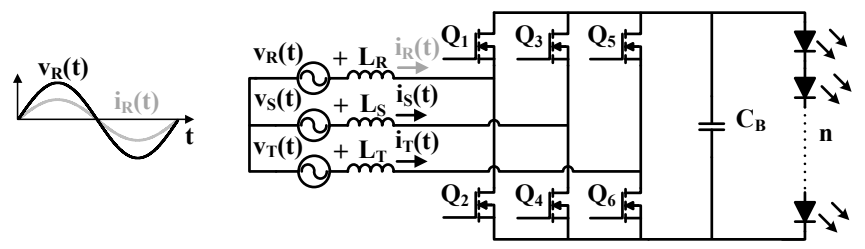

(a)

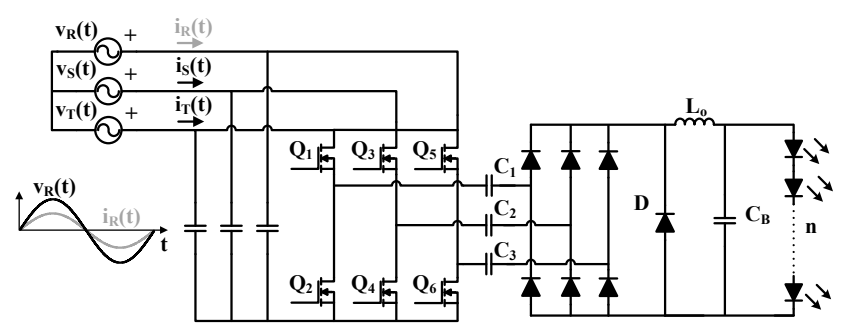

(b)

Fig. 17. Multi-switch three-phase ac-dc solutions for LED drivers. (a) Boost converter. (b) Resonant switched capacitor LED driver [210].

means of switched capacitor converters, see Fig. 17 (b) [210]. These ac-dc LED drivers can achieve high power density, high efficiency, do not require current sensing to maintain a stable light and can have lower output voltages. In contrast, the proposal requires variable frequency operation, controls the voltage withstood by the LED load instead of its current, cannot achieve full dimming condition and require several active switches and diodes, which will hinder its reliability.

\section{B. Multi-stage}

Another possibility to attain input sinusoidal waveforms is the use of multi-stage solutions. Unlike single-phase ac-dc multi-stage solutions, in which the isolated dc-dc converter could remove the low frequency ripple across the LED load, three-phase ac-dc LED drivers can naturally remove the low frequency ripple with a single-stage, hence, disposing the electrolytic capacitor due to the non-pulsation of the power grid on the load. Therefore, the actual use of this second stage would be focused on adapting the voltage and current levels to those required by the LED load and provide galvanic isolation. For that matter, the purpose of the second stage is closer to the post-regulator or third stage of the single-phase ac-dc multi-stage scheme. The topologies normally used for the second stage are similarly based on the ones introduced for the single-phase multi-stage LED drivers due to the requirement of a high step-down gain [223], [224] (i.e., LLC or AHB).

In regard to the first stage, it is traditionally comprised of the three-phase multi-switch ac-dc boost previously introduced, because of its higher efficiency and its ability to achieve PFC. This higher efficiency becomes necessary in order to be able to compete with single-stage based solutions as the two stages will hinder the efficiency of the three-phase ac-dc LED driver. However, one of the main advantages, which is bi-directionality, will not be leveraged with an LED load. In addition, the increased amount of components, which increment cost and diminish reliability, the arguably lower efficiency of the whole driver and the lack of purpose of the second stage responsible for removing the electrolytic capacitor in the single-phase scenario, have made the use of three-phase multi-stage ac-dc LED drivers unattractive.

\section{Multi-cell solutions}

One of the simplest ways in which a three-phase rectifier can be developed was proposed by Delco as a three-phase rectifier using thyristors as the main switches for a resistive load [225]. The approach is based on having several ac-dc converters with PFC (i.e., PFC converters), which will be defined as cells, each connected to a phase and working as an LFR, see Fig. 18. These ac-dc converters require galvanic isolation in order to be able to connect their outputs in parallel. By doing so, the electrolytic capacitor can be removed as there is no actual pulsation of power on the load. However, this reduces the potential topologies that can be used for this task.

The Delco topology was proposed as a three-phase ac-dc LED driver in [226] where it was compared to the multi-cell ac-dc LED driver based on the three-phase rectifier [226], [227], see Fig. 19. The study shows that both topologies comply with the required regulations and recommendations while disposing of the electrolytic capacitor. In addition, the comparison shows that the multi-cell ac-dc LED driver based on the three-phase full-wave rectifier performs better in terms of efficiency at the cost of having an increased number of cells and components. Nonetheless, their efficiency is still low, as it barely reaches $90 \%$, which actually happens due to the implementation of the cells with flyback dc-dc converters.

Moreover, the design of each module is equivalent to that of a single-phase ac-dc converter with PFC, which simplifies and improves the power scaling of the ac-dc LED driver, considering the modularity of the solution. As has been mentioned before, an LFR performance is required to attain PFC, particularly for this case with galvanic isolation. Therefore, the simplest way to achieve this performance is by

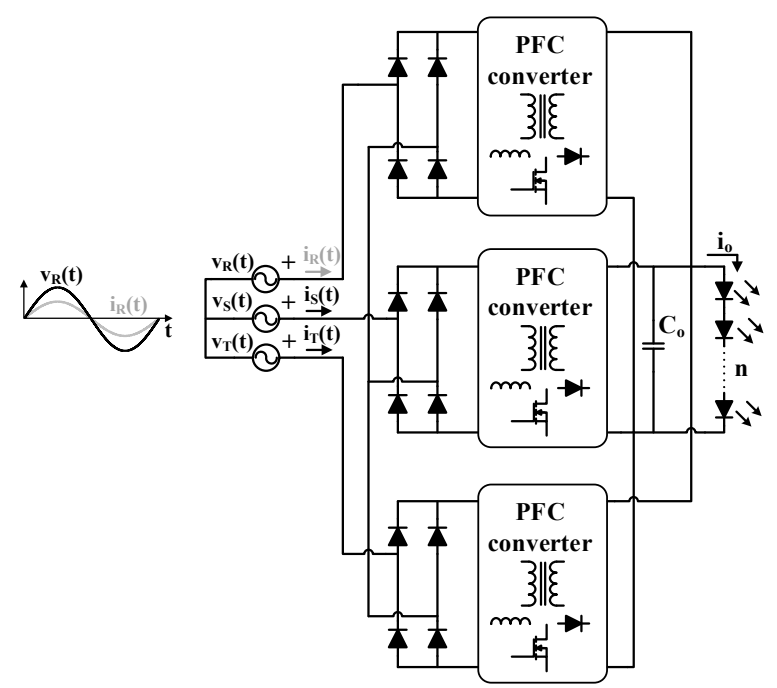

Fig. 18. Delco ac-dc LED driver [226]. 
means of an isolated topology from the buck-boost family working in DCM. For that matter, some authors have proposed to use the following topologies as cells, the flyback converter [228], [229], the Ćuk converter [230] or the SEPIC converter [231]. The issue being the same one introduced before regarding the low efficiencies achieved by these converters in comparison with a two-stage solution. Therefore, it is also possible as introduced by other authors, the use of a two-stage cell approach in order to achieve higher efficiencies [232], or any of the quasi-single-stages introduced in Section III.B.1). In contrast, the control and amount of components included in this solution increases dramatically, becoming of interest for high power luminaires (i.e., $>1 \mathrm{~kW}$ ).

In order to improve the efficiency, the multi-cell ac-dc LED driver based on summing the light output of each phase has been proposed in [233], see Fig. 20. The proposal is based on using a highly efficient cell without an electrolytic capacitor, disregarding whether it provides galvanic isolation or not, and connecting an LED load directly to each cell. The total light output of this ac-de LED driver would be constant, being the sum of lights of each phase, which is a method that was used during the Beijing 2008 Summer Olympics in the National Stadium, also known as Bird's nest, with several spotlights each of $1.5 \mathrm{~kW}$ and $125,000 \mathrm{~lm}$ [235]. In addition, [233] is able achieve a high efficiency, comply the regulations and achieve a very low Mod. (\%), at the cost of having to correctly position the LED loads to adequately blend the light output and having an increased low frequency ripple across the LED loads.

These multi-cell approaches are more complex from a control point of view since they add more components and are arguably more expensive than the three-phase single-switch single-stage ac-dc LED drivers, which typically require the use of a central control unit. This central control unit will be responsible for ensuring that each of the modules processes the same amount of power and that correctly starts-up, normally requiring digital control for this purpose. In contrast, they have a better trade-off between output voltage and THD than the aforementioned three-phase single-switch singlestage ac-dc LED drivers.

In a similar fashion to what was done for single-phase acdc LED drivers, Table IV summarizes the advantages and disadvantages of the several three-phase ac-dc LED drivers that have been discussed, as well as, listing the achievements and design parameters. In this particular case, it can be easily seen that the biggest advantages is the straight removal of the electrolytic capacitor. It should be noted, that these considerations are made in a general way and specific solutions may have additional advantages and disadvantages.

\section{CONCLUSIONS}

A comprehensive and generalized review of ac-dc LED drivers have been carried out taking into account the latest trends and considering the specific regulations and recommendations that ac-dc LED drivers need to comply with, nowadays. This review has led to classify ac-dc LED drivers into two major categories depending on which ac

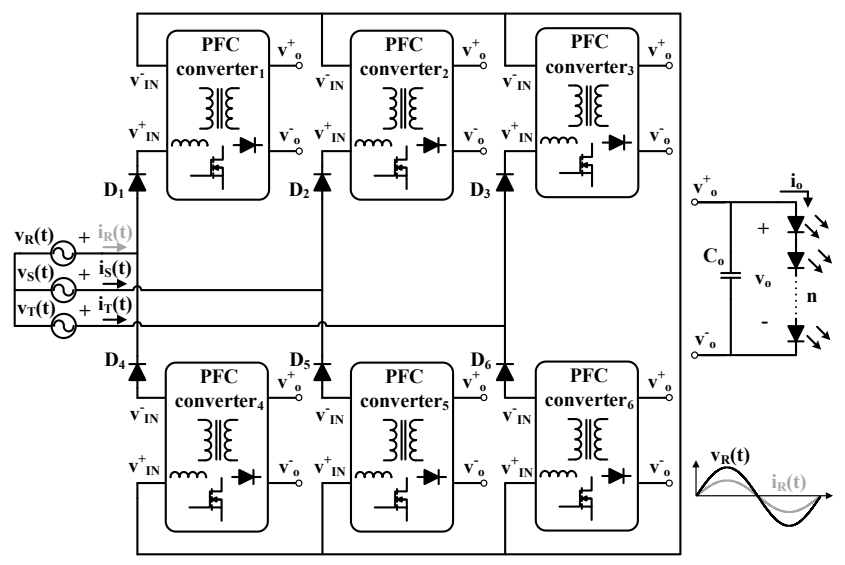

Fig. 19. Multi-cell ac-dc LED driver based on the three-phase full-wave rectifier [226], [227].

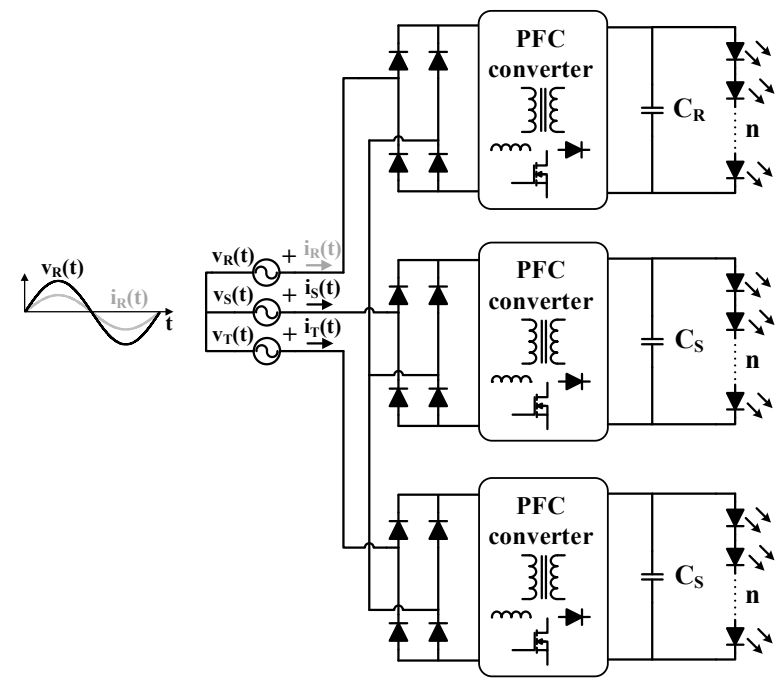

Fig. 20. Multi-cell ac-dc LED driver based on summing the light output of each phase [233], [234].

power grid they are connected to: single-phase or three-phase. From these two major categories, the ac-dc LED drivers are then classified into four minor categories for single-phase and three for three-phase taking into consideration the amount of power stages used. These categories that are discussed throughout the review are summarized into Tables III and IV, for the designer to understand the advantages and disadvantages of state-of-the-art ac-dc LED drivers and see at a glance the benefits of each of the categories and solutions.

The aim of the publications on the topic of flicker-free acdc LED drivers can be typically summarized on increasing the efficiency, reducing the cost and removing the most limiting component in terms of lifetime, which is the electrolytic capacitor. Particularly for lamps (i.e., $<25 \mathrm{~W}$ ) in single-phase ac power grids, the use of passive solutions has been widespread with only a handful of works carried out for active solutions where the aim is a single-stage without an electrolytic. 
TABLE IV. SUMMARY OF THREE-PHASE FLICKER-FREE AC-DC LED DRIVERS

AdVANTAGEs

DisAdVANTAGE
EFFICIENCY

(\%)
THD

(\%)

\section{UNIVERSAL}

INPUT
Control

DIMMING

ICKER-FRE

CONDITION

\begin{tabular}{|c|c|c|c|c|c|c|c|c|c|}
\hline $\begin{array}{l}\text { Single-stage: } \\
\text { Single-switch } \\
\text { [209] }\end{array}$ & $\begin{array}{ll}\text { - } & \text { Low component count. } \\
\text { - } & \text { Simplicity. } \\
& \text { Galvanic isolation. }\end{array}$ & $\begin{array}{l}\text { - High stress on the main switch. } \\
\text { May require a high output voltage } \\
\text { to sustain a sinusoidal input } \\
\text { current. } \\
\text { - Very low efficiency. } \\
\text { It would require an extra stage for } \\
\text { current sharing. }\end{array}$ & 75 [209] & 99 & 7 & No & Analog & Yes & $\begin{array}{l}\text { Electrolytic capacitor } \\
\text { removed }\end{array}$ \\
\hline $\begin{array}{l}\text { Single-stage: } \\
\text { Multi-switch } \\
\text { [210] }\end{array}$ & $\begin{array}{ll}\text { - } & \text { Compact. } \\
\text { - } & \text { High efficiency. }\end{array}$ & $\begin{array}{l}\text { - High component count. } \\
\text { - } \quad \text { It would control. } \\
\text { ensure current sharing. } \\
\text { - No galvanic isolation. }\end{array}$ & 91 [210] & 99 & 4 & No & Analog & Yes & $\begin{array}{l}\text { Electrolytic capacitor } \\
\text { removed }\end{array}$ \\
\hline Multi-stage & $\begin{array}{ll}\text { - } & \text { High efficiency. } \\
\text { - } & \text { Traditional first stage. } \\
\text { Galvanic isolation. }\end{array}$ & $\begin{array}{l}\text { - Very high component count. } \\
\text { Second stage is merely used to } \\
\text { adequate voltage and current } \\
\text { levels to the LED load. }\end{array}$ & - & - & - & - & - & - & $\begin{array}{l}\text { Electrolytic capacitor } \\
\text { removed }\end{array}$ \\
\hline $\begin{array}{l}\text { Mutli.cell: } \\
\text { Traditional } \\
\text { [226], [227] }\end{array}$ & $\begin{array}{ll}\text { - } & \text { Modular. } \\
\text { - } & \text { Scalability. } \\
& \text { Galvanic isolation. }\end{array}$ & $\begin{array}{l}\text { - Very high component count. } \\
\text { - Reduced amount of topologies, as } \\
\text { galvanic isolation is mandatory } \\
\text { and they also need to operate as } \\
\text { LFRs. } \\
\text { - Complex control. } \\
\text { - Cell tolerances. }\end{array}$ & $\begin{array}{l}88[226], \\
90[227]\end{array}$ & 99 & 5 & No & Digital & Yes & $\begin{array}{l}\text { Electrolytic capacitor } \\
\text { removed }\end{array}$ \\
\hline $\begin{array}{l}\text { Multi-cell: } \\
\text { Light } \\
\text { summing } \\
{[233],[234]}\end{array}$ & $\begin{array}{l}\text { - Modular. } \\
\text { - } \quad \text { Scalability. } \\
\text { Any LFR can be used as the cell } \\
\text { of this topology. } \\
\text { - Very high efficiency. }\end{array}$ & $\begin{array}{l}\text { - } \quad \text { Very high component count. } \\
\text { - } \quad \text { corre LED load needs to be } \\
\text { flicker-free opitioned to ensure } \\
\text { - Very high component count. } \\
\text { - Complex control. } \\
\text { - } \quad \text { Cell tolerances. } \\
\text { - } \quad \text { May require HV LEDs }\end{array}$ & $\begin{array}{c}97.5[233] \\
\quad[234]\end{array}$ & 99 & 7 & No & Digital & Yes & $\begin{array}{l}\text { Electrolytic capacitor } \\
\text { removed }\end{array}$ \\
\hline
\end{tabular}


However, the simplicity and cost efficiency of passive ac-dc LED drivers makes them overall a more attractive solution for LED lamps. In contrast, for LED luminaires (i.e., > $25 \mathrm{~W}$ ) in single-phase ac power grids that require a much restrictive regulation, the achievement of dimming, a high light quality, a high efficiency, galvanic isolation, a flicker-free performance and the removal of the electrolytic capacitor are almost mandatory, leading to consider apart from quasi-single-stage, the traditional two-stage or even multi-stage approach. However, only the latter is able to achieve all those benefits within an LED driver, whereas most of the quasi-single-stages require to trade-off some of them.

Considering the ubiquity of LEDs among lighting products and the aim for high power luminaires, a handful of works have been developed around three-phase ac-dc LED drivers for commercial and industrial installations. In this particular case, the removal of the electrolytic capacitor becomes immediate, but at the cost of attaining a more complex ac-dc LED driver, which needs to achieve a high efficiencies due to the power consumed by the luminaire (i.e., $>250 \mathrm{~W}$ ). For low and medium power ranges, the use of single-switch solutions is the simplest solution, disregarding the fact that a current sharing technique will be required. As regards high power LED luminaires multiswitch and multi-cell topologies become more atractive due to their higher efficiencies, and their ability to process more power. Particularly multi-cell topologies due to their scalibility, as they are able to add as many optimized cells or modules as required. However, they would still require the use of a current sharing techniques to ensure that the same current goes across all the LED strings of the LED load, unless a multi-cell ac-dc LED driver based on light summing is used, whose cells also performs as the post-regulator stage.

\section{REFERENCES}

[1] D. Karunatilaka, F. Zafar, V. Kalavally and R. Parthiban, "LED Based Indoor Visible Light Communications: State of the Art," in IEEE Communications Surveys \& Tutorials, vol. 17, no. 3, pp. 1649-1678, thirdquarter 2015.

[2] J. Sebastian, D. G. Aller, J. Rodriguez, D. G. Lamar and P. F. Miaja, "On the role of the power electronics on visible light communication," 2017 IEEE Applied Power Electronics Conference and Exposition (APEC), Tampa, FL, 2017, pp. 2420-2427.

[3] J. Rodriguez, D. G. Lamar, D. G. Aller, Pablo F. Miaja and J. Sebastian, "Efficient Visible Light Communication Transmitters Based on Switching-Mode dc-dc Converters, " in Sensors, vol. 18, no. 4, pp., Apr. 2018.

[4] R. F. Karlicek, "Smart lighting - Beyond simple illumination," 2012 IEEE Photonics Society Summer Topical Meeting Series, Seattle, WA, 2012, pp. 147-148.

[5] R. F. Karlicek, "Smart lighting and the Future of Illumination Markets," Industry Session, 2016 IEEE Applied Power Electronics Conference and Exposition (APEC), Long Beach, CA, 2016.

[6] Sean King, "Luminous Intensity of an LED as a Function of Input Power", ISB Journal of Physics, June 2008.
[7] N. Pousset, B. Rougie, and A. Razet, "Impact of current supply on LED colour," Lighting Res. Technol., vol. 42, no.4, pp. 371-383, August 2010.

[8] S. Winder, "Characteristics of LEDs" in Power supplies for LED driving, 2nd edition, USA, Newnes, 2016, ch. 2, pp. 9-15.

[9] Lumiled, "Luxeon Rebel ES," Product Datasheet, Lumileds Holding B.V., 2016.

[10] Cree, "Cree ${ }^{\circledR}$ XLamp ${ }^{\circledR}$ XB-D LEDs," Product Datasheet, Cree Inc., 2017.

[11] OSRAM, "OSRAM OSLON ${ }^{\circledR}$ SSL 150," Product Datasheet, OSRAM, 2015.

[12] M. Wright, "Strategies Unlimited tempers LED ad SSL projections but remains bullish on sectors," LEDs magazine, vol. 12, no. 4, pp. 31-42, April 2015.

[13] M. Arias, A. Vazquez, and J. Sebastian, "An overview of the AC-DC and DC-DC converters for LED lighting applications," Automatika-J. Control, Measure., Electr., Comput. Commun., vol. 53, pp. 156-172, 2012.

[14] ENERGY STAR ${ }^{\circledR}$ Certified Lighting: What types of products earn the label?

[15] ENERGY STAR ${ }^{\circledR}$ Program Requirements Product Specification for Lamps (Light Bulbs) - Elegibility Criteria, V. 2.0, Oct. 2016.

[16] ENERGY STAR ${ }^{\circledR}$ Program Requirements Product Specification for Luminaires (Light Fixtures) - Elegibility Criteria, V. 2.0, Jan. 2016.

[17] W. J. Sarjeant, J. Zirnheld and F. W. MacDougall, "Capacitors," in IEEE Transactions on Plasma Science, vol. 26, no. 5, pp. 1368-1392, Oct 1998.

[18] Electromagnetic compatibility (EMC) - Part 3-2: Limits Limits for harmonic current emissions (equipment input current $<16$ A per phase), document IEC 61000-3-2, 2014.

[19] M. S. Rea, Ed. "The IESNA Lighting Handbook: Reference and Application", 9th ed. NY: Illuminating Eng. Soc. of North Amer., 2000.

[20] B. Lehman, A. Wilkins, S. Berman, M. Poplawski, and N. Miller, "Proposing metrics of flicker in the low frequencies for lighting applications, " LEUKOS, vol. 7, pp. 189-195, 2011.

[21] D. DiLaura, K. W. Houser, R. G. Misrtrick, R. G. Steffy, "The Lighting Handbook," 10th edition, Illuminating Engineering Society of North America 120, 2011.

[22] B. Lehman and A. J. Wilkins, "Designing to Mitigate Effects of Flicker in LED Lighting: Reducing risks to health and safety," in IEEE Power Electronics Magazine, vol. 1, no. 3, pp. 18-26, Sept. 2014.

[23] "IEEE Recommended Practices for Modulating Current in High-Brightness LEDs for Mitigating Health Risks to Viewers," in IEEE Std 1789-2015, vol., no., pp.1-80, June 52015.

[24] Flickermeter-Functional and Design Specifications, IEC Standard 61000- 4-15, 2012. 
[25] P. Erwin and P. Shackle, "Understand a new flicker metric and its application to AC-LED light engines," LEDs magazine, no. 96, pp. 55-62, April 2017.

[26] A. Bierman, "Recommended metric for assessing the direct perception of light source flicker," ASSIST recommends, vol. 11, no. 3, January 2015.

[27] NEMA Standards Publication 77-2017, "Temporal Light Artifacts: Test Methods and Guidance for Acceptance Criteria, " National Electrical Manufacturers Association, 2017.

[28] M. Perz, I. Vogels, D. Sekulovski, L. Wang, Y. Tu, I. E. J. Heynderickx, "Modeling the visibility of the stroboscopic effect occurring in temporally modulated light systems", Light. Res. Technol., vol. 46, no. 3, 2014.

[29] CIE TN 008:2017, "CIE Stakeholder Workshop for Temporal Light Modulation Standards for Lighting Systems, " International Commission on Illumination, 2017.

[30] R. Zhang and H. S. h. Chung, "A TRIAC-Dimmable LED Lamp Driver With Wide Dimming Range," in IEEE Transactions on Power Electronics, vol. 29, no. 3, pp. 1434-1446, March 2014.

[31] P. Richman, "Wave Factors for Rectifiers with Capacitor Input Filters, and Other High Crest-Factor Loads," in IEEE Transactions on Industrial Electronics and Control Instrumentation, vol. IECI-21, no. 4, pp. 235-241, Nov. 1974.

[32] N. O. Sokal, K. Sum and D. C. Hamill, "A capacitor-fed, voltage-step-down, single-phase, nonisolated rectifier," Applied Power Electronics Conference and Exposition, 1998. APEC '98. Conference Proceedings 1998., Thirteenth Annual, Anaheim, CA, 1998, pp. 208215 vol.1.

[33] R. Dayal, K. Modepalli and L. Parsa, "A direct AC LED driver with high power factor without the use of passive components," 2012 IEEE Energy Conversion Congress and Exposition (ECCE), Raleigh, NC, 2012, pp. 42304234.

[34] Sanghyun Cha et al., "AC/DC converter free LED driver for lightings," 2012 IEEE International Conference on Consumer Electronics (ICCE), Las Vegas, NV, 2012, pp. 706-708.

[35] K. I. Hwu and W. C. Tu, "Controllable and Dimmable AC LED Driver Based on FPGA to Achieve High PF and Low THD," in IEEE Transactions on Industrial Informatics, vol. 9, no. 3, pp. 1330-1342, Aug. 2013.

[36] K. I. Hwu, W. C. Tu and Y. T. Fang, "Dimmable AC LED Driver With Efficiency Improved Based on Switched LED Module," in Journal of Display Technology, vol. 10, no. 3, pp. 171-181, March 2014.

[37] Hongbo Gao et al., "An electrolytic-capacitorless and inductorless AC direct LED driver with power compensation," 2015 IEEE 2nd International Future Energy Electronics Conference (IFEEC), Taipei, 2015, pp. $1-5$.
[38] Y. Noge, "Linear AC LED driver with the multi-level structure and variable current regulator," 2015 9th International Conference on Power Electronics and ECCE Asia (ICPE-ECCE Asia), Seoul, 2015, pp. 964-969.

[39] W. Feng, Y. He and F. G. Shi, "Investigation of LED Light Output Performance Characteristics Under Different Alternating Current Regulation Modes," in IEEE Journal of Selected Topics in Quantum Electronics, vol. 17, no. 3, pp. 720-723, May-June 2011.

[40] S. M. Baddela and D. S. Zinger, "Parallel connected LEDs operated at high to improve current sharing," Conference Record of the 2004 IEEE Industry Applications Conference, 2004. 39th IAS Annual Meeting., 2004, pp. 1677-1681 vol.3.

[41] K. I. Hwu and S. C. Chou, "A Simple Current-Balancing Converter for LED Lighting," 2009 Twenty-Fourth Annual IEEE Applied Power Electronics Conference and Exposition, Washington, DC, 2009, pp. 587-590.

[42] K. Zhou, J. G. Zhang, S. Yuvarajan and D. F. Weng, "Quasi-Active Power Factor Correction Circuit for HB LED Driver," in IEEE Transactions on Power Electronics, vol. 23, no. 3, pp. 1410-1415, May 2008.

[43] S. Y. Hui, S. N. Li, X. H. Tao, W. Chen and W. M. Ng, "A Novel Passive Offline LED Driver With Long Lifetime," in IEEE Transactions on Power Electronics, vol. 25, no. 10, pp. 2665-2672, Oct. 2010.

[44] W. Chen, S. N. Li and S. Y. R. Hui, "A comparative study on the circuit topologies for offline passive light-emitting diode (LED) drivers with long lifetime \& high efficiency," 2010 IEEE Energy Conversion Congress and Exposition, Atlanta, GA, 2010, pp. 724-730.

[45] E. S. Lee, B. H. Choi, J. P. Cheon, G. C. Lim, B. C. Kim and C. T. Rim, "Temperature-Robust LC $^{3}$ Passive LED Drivers With Low THD, High Efficiency and PF, and Long Life," in IEEE Journal of Emerging and Selected Topics in Power Electronics, vol. 3, no. 3, pp. 829-840, Sept. 2015.

[46] S. Buso, G. Spiazzi and F. Sichirollo, "Study of the Asymmetrical Half-Bridge Flyback Converter as an Effective Line-Fed Solid-State Lamp Driver," in IEEE Transactions on Industrial Electronics, vol. 61, no. 12, pp. 6730-6738, Dec. 2014.

[47] H. Ma, J. S. Lai, Q. Feng, W. Yu, C. Zheng and Z. Zhao, "A Novel Valley-Fill SEPIC-Derived Power Supply Without Electrolytic Capacitor for LED Lighting Application," in IEEE Transactions on Power Electronics, vol. 27, no. 6, pp. 3057-3071, June 2012.

[48] H. Ma, C. Zheng, W. Yu, B. Gu, J. D. Lai and Q. Feng, "Bridgeless electrolytic capacitor-less valley-fill AC/DC converter for offline twin-bus light-emitting diode lighting application," in IET Power Electronics, vol. 6, no. 6, pp. 1132-1141, July 2013.

[49] L. Wang, B. Zhang and D. Qiu, "A Novel Valley-Fill Single-Stage Boost-Forward Converter With Optimized Performance in Universal-Line Range for Dimmable LED 
Lighting," in IEEE Transactions on Industrial Electronics, vol. 64, no. 4, pp. 2770-2778, April 2017.

[50] L. Gu, X. Ruan, M. Xu and K. Yao, "Means of Eliminating Electrolytic Capacitor in AC/DC Power Supplies for LED Lightings," in IEEE Transactions on Power Electronics, vol. 24, no. 5, pp. 1399-1408, May 2009.

[51] B. Wang, X. Ruan, K. Yao and M. Xu, "A Method of Reducing the Peak-to-Average Ratio of LED Current for Electrolytic Capacitor-Less AC-DC Drivers," in IEEE Transactions on Power Electronics, vol. 25, no. 3, pp. 592601, March 2010.

[52] X. Ruan, B. Wang, K. Yao and S. Wang, "Optimum Injected Current Harmonics to Minimize Peak-to-Average Ratio of LED Current for Electrolytic Capacitor-Less ACDC Drivers," in IEEE Transactions on Power Electronics, vol. 26, no. 7, pp. 1820-1825, July 2011.

[53] D. G. Lamar, J. Sebastian, M. Arias and A. Fernandez, "On the Limit of the Output Capacitor Reduction in PowerFactor Correctors by Distorting the Line Input Current," in IEEE Transactions on Power Electronics, vol. 27, no. 3, pp. 1168-1176, March 2012.

[54] G. Spiazzi, S. Buso and G. Meneghesso, "Analysis of a High-Power-Factor Electronic Ballast for High Brightness Light Emitting Diodes," 2005 IEEE 36th Power Electronics Specialists Conference, Recife, 2005, pp. 1494-1499.

[55] X. Qu, S. C. Wong and C. K. Tse, "Resonance-Assisted Buck Converter for Offline Driving of Power LED Replacement Lamps," in IEEE Transactions on Power Electronics, vol. 26, no. 2, pp. 532-540, Feb. 2011.

[56] D. G. Lamar, M. Fernandez, M. Arias, M. M. Hernando and J. Sebastian, "Tapped-Inductor Buck HB-LED ACDC Driver Operating in Boundary Conduction Mode for Replacing Incandescent Bulb Lamps," in IEEE Transactions on Power Electronics, vol. 27, no. 10, pp. 4329-4337, Oct. 2012.

[57] F. Sichirollo, J. M. Alonso and G. Spiazzi, "A Novel Double Integrated Buck Offline Power Supply for SolidState Lighting Applications," in IEEE Transactions on Industry Applications, vol. 51, no. 2, pp. 1268-1276, March-April 2015.

[58] J. B. Baek and S. Chae, "Single-Stage Buck-Derived LED Driver With Improved Efficiency and Power Factor Using Current Path Control Switches," in IEEE Transactions on Industrial Electronics, vol. 64, no. 10, pp. 7852-7861, Oct. 2017.

[59] H. C. Kim, M. C. Choi, S. Kim and D. K. Jeong, "An ACDC LED Driver With a Two-Parallel Inverted Buck Topology for Reducing the Light Flicker in Lighting Applications to Low-Risk Levels," in IEEE Transactions on Power Electronics, vol. 32, no. 5, pp. 3879-3891, May 2017.

[60] I. H. Codas, C. S. Postiglione, C. B. Nascimento and A. J. Perin, "A single-stage PFC converter for Solid-State
Lighting applications," 2009 35th Annual Conference of IEEE Industrial Electronics, Porto, 2009, pp. 3490-3493.

[61] S. Singer, "Realization of loss-free resistive elements," in IEEE Transactions on Circuits and Systems, vol. 37, no. 1, pp. 54-60, Jan 1990.

[62] S. Singer and R. W. Erickson, "Power-source element and its properties," in IEE Proceedings - Circuits, Devices and Systems, vol. 141, no. 3, pp. 220-226, Jun 1994.

[63] O. Garcia, J. A. Cobos, R. Prieto, P. Alou and J. Uceda, "Single phase power factor correction: a survey," in IEEE Transactions on Power Electronics, vol. 18, no. 3, pp. 749755, May 2003.

[64] G. G. Pereira, M. A. Dalla Costa, J. M. Alonso, M. F. De Melo and C. H. Barriquello, "LED Driver Based on Input Current Shaper Without Electrolytic Capacitor," in IEEE Transactions on Industrial Electronics, vol. 64, no. 6, pp. 4520-4529, June 2017.

[65] C. Branas, F. J. Azcondo and J. M. Alonso, "Solid-State Lighting: A System Review," in IEEE Industrial Electronics Magazine, vol. 7, no. 4, pp. 6-14, Dec. 2013.

[66] P. S. Almeida, D. Camponogara, M. Dalla Costa, H. Braga and J. M. Alonso, "Matching LED and Driver Life Spans: A Review of Different Techniques," in IEEE Industrial Electronics Magazine, vol. 9, no. 2, pp. 36-47, June 2015.

[67] S. Li, S. C. Tan, C. K. Lee, E. Waffenschmidt, S. Y. (. Hui and C. K. Tse, "A Survey, Classification, and Critical Review of Light-Emitting Diode Drivers," in IEEE Transactions on Power Electronics, vol. 31, no. 2, pp. 1503-1516, Feb. 2016.

[68] Y. Wang, J. M. Alonso and X. Ruan, "A Review of LED Drivers and Related Technologies," in IEEE Transactions on Industrial Electronics, vol. 64, no. 7, pp. 5754-5765, July 2017.

[69] R. Erickson, M. Madigan and S. Singer, "Design of a simple high-power-factor rectifier based on the flyback converter," Fifth Annual Proceedings on Applied Power Electronics Conference and Exposition, Los Angeles, CA, USA, 1990, pp. 792-801.

[70] R. Watson, G. C. Hua and F. C. Lee, "Characterization of an active clamp flyback topology for power factor correction applications," in IEEE Transactions on Power Electronics, vol. 11, no. 1, pp. 191-198, Jan 1996.

[71] E. J. Rikos and E. C. Tatakis, "Single-stage single-switch isolated PFC converter with non-dissipative clamping," in IEE Proceedings - Electric Power Applications, vol. 152, no. 2, pp. 166-174, 4 March 2005.

[72] H. van der Broeck, G. Sauerlander and M. Wendt, "Power driver topologies and control schemes for LEDs," APEC 07 - Twenty-Second Annual IEEE Applied Power Electronics Conference and Exposition, Anaheim, CA, USA, 2007, pp. 1319-1325.

[73] Y. Hu, L. Huber and M. M. Jovanovic, "Single-Stage Flyback Power-Factor-Correction Front-End for HB LED Application," 2009 IEEE Industry Applications Society Annual Meeting, Houston, TX, 2009, pp. 1-8. 
[74] D. G. Lamar, J. S. Zúñiga, A. R. Alonso, M. R. González and M. M. Hernando Álvarez, "A Very Simple Control Strategy for Power Factor Correctors Driving HighBrightness LEDs," in IEEE Transactions on Power Electronics, vol. 24, no. 8, pp. 2032-2042, Aug. 2009.

[75] K. I. Hwu, Y. T. Yau and L. L. Lee, "Powering LED Using High-Efficiency SR Flyback Converter," in IEEE Transactions on Industry Applications, vol. 47, no. 1, pp. 376-386, Jan.-Feb. 2011.

[76] W. Chen and S. Y. R. Hui, "Elimination of an Electrolytic Capacitor in AC/DC Light-Emitting Diode (LED) Driver With High Input Power Factor and Constant Output Current," in IEEE Transactions on Power Electronics, vol. 27, no. 3, pp. 1598-1607, March 2012.

[77] Y. Hu, L. Huber and M. M. Jovanović, "Single-Stage, Universal-Input AC/DC LED Driver With CurrentControlled Variable PFC Boost Inductor," in IEEE Transactions on Power Electronics, vol. 27, no. 3, pp. 1579-1588, March 2012.

[78] J. M. Alonso, D. Gacio, A. J. Calleja, J. Ribas and E. L. Corominas, "A Study on LED Retrofit Solutions for LowVoltage Halogen Cycle Lamps," in IEEE Transactions on Industry Applications, vol. 48, no. 5, pp. 1673-1682, Sept.Oct. 2012.

[79] X. Xie, J. Wang, C. Zhao, Q. Lu and S. Liu, "A Novel Output Current Estimation and Regulation Circuit for Primary Side Controlled High Power Factor Single-Stage Flyback LED Driver," in IEEE Transactions on Power Electronics, vol. 27, no. 11, pp. 4602-4612, Nov. 2012.

[80] X. Wu, Z. Wang and J. Zhang, "Design Considerations for Dual-Output Quasi-Resonant Flyback LED Driver With Current-Sharing Transformer," in IEEE Transactions on Power Electronics, vol. 28, no. 10, pp. 4820-4830, Oct. 2013.

[81] S. Jung and G. H. Cho, "Transformer Coupled Recycle Snubber for High-Efficiency Offline Isolated LED Driver With On-Chip Primary-Side Power Regulation," in IEEE Transactions on Industrial Electronics, vol. 61, no. 12, pp. 6710-6719, Dec. 2014.

[82] S. Moon, G. B. Koo and G. W. Moon, "Dimming-Feedback Control Method for TRIAC Dimmable LED Drivers," in IEEE Transactions on Industrial Electronics, vol. 62, no. 2, pp. 960-965, Feb. 2015.

[83] B. White, H. Wang, Y. F. Liu and X. Liu, "An Average Current Modulation Method for Single-Stage LED Drivers With High Power Factor and Zero Low-Frequency Current Ripple," in IEEE Journal of Emerging and Selected Topics in Power Electronics, vol. 3, no. 3, pp. 714-731, Sept. 2015.

[84] D. G. Lamar, M. Arias, M. M. Hernando and J. Sebastian, "Using the Loss-Free Resistor Concept to Design a Simple AC-DC HB-LED Driver for Retrofit Lamp Applications," in IEEE Transactions on Industry Applications, vol. 51, no. 3, pp. 2300-2311, May-June 2015.

[85] D. G. Lamar, M. Arias, A. Fernandez, J. A. Villarejo and J. Sebastian, "Active Input Current Shaper Without an
Electrolytic Capacitor for Retrofit Lamps Applications," in IEEE Transactions on Power Electronics, vol. 32, no. 5, pp. 3908-3919, May 2017.

[86] H. L. Cheng, Y. N. Chang, C. H. Chang, S. Y. Hsieh and C. A. Cheng, "A Novel High-Power-Factor AC/DC LED Driver with Dual Flyback Converters," in IEEE Journal of Emerging and Selected Topics in Power Electronics.

[87] D. D. C. Lu, H. H. C. Iu and V. Pjevalica, "A Single-Stage AC/DC Converter With High Power Factor, Regulated Bus Voltage, and Output Voltage," in IEEE Transactions on Power Electronics, vol. 23, no. 1, pp. 218-228, Jan. 2008.

[88] K. Yao, M. Xu, X. Ruan and L. Gu, "Boost-Flyback Single-Stage PFC Converter with Large DC Bus Voltage Ripple," 2009 Twenty-Fourth Annual IEEE Applied Power Electronics Conference and Exposition, Washington, DC, 2009, pp. 1867-1871.

[89] D. D. C. Lu, H. H. C. Iu and V. Pjevalica, "Single-Stage AC/DC Boost-Forward Converter With High Power Factor and Regulated Bus and Output Voltages," in IEEE Transactions on Industrial Electronics, vol. 56, no. 6, pp. 2128-2132, June 2009.

[90] S. Y. Chen, Z. R. Li and C. L. Chen, "Analysis and Design of Single-Stage AC/DC LLC Resonant Converter," in IEEE Transactions on Industrial Electronics, vol. 59, no. 3, pp. 1538-1544, March 2012.

[91] N. Chen and H. S. h. Chung, "An LED Lamp Driver Compatible With Low- and High-Frequency Sources," in IEEE Transactions on Power Electronics, vol. 28, no. 5, pp. 2551-2568, May 2013.

[92] Y. Wang, Y. Guan, K. Ren, W. Wang and D. Xu, "A Single-Stage LED Driver Based on BCM Boost Circuit and LLC Converter for Street Lighting System," in IEEE Transactions on Industrial Electronics, vol. 62, no. 9, pp. 5446-5457, Sept. 2015.

[93] Q. Luo, K. Ma, Q. He, C. Zou and L. Zhou, "A SingleStage High-Frequency Resonant AC/AC Converter," in IEEE Transactions on Power Electronics, vol. 32, no. 3, pp. 2155-2166, March 2017.

[94] C. A. Cheng, H. L. Cheng and T. Y. Chung, "A Novel Single-Stage High-Power-Factor LED Street-Lighting Driver With Coupled Inductors," in IEEE Transactions on Industry Applications, vol. 50, no. 5, pp. 3037-3045, Sept.Oct. 2014.

[95] P. S. Almeida, H. A. C. Braga, M. A. Dalla Costa and J. M. Alonso, "Offline Soft-Switched LED Driver Based on an Integrated Bridgeless Boost-Asymmetrical Half-Bridge Converter," in IEEE Transactions on Industry Applications, vol. 51, no. 1, pp. 761-769, Jan.-Feb. 2015.

[96] C. A. Cheng, C. H. Chang, T. Y. Chung and F. L. Yang, "Design and Implementation of a Single-Stage Driver for Supplying an LED Street-Lighting Module With Power Factor Corrections," in IEEE Transactions on Power Electronics, vol. 30, no. 2, pp. 956-966, Feb. 2015.

[97] A. Malschitzky, F. Albuquerque, E. Agostini and C. B. Nascimento, "Single-Stage Integrated Bridgeless-Boost 
Nonresonant Half-Bridge Converter for LED Driver Applications," in IEEE Transactions on Industrial Electronics, vol. 65, no. 5, pp. 3866-3878, May 2018.

[98] X. Xie, J. Li, K. Peng, C. Zhao and Q. Lu, "Study on the Single-Stage Forward-Flyback PFC Converter With QR Control," in IEEE Transactions on Power Electronics, vol. 31, no. 1, pp. 430-442, Jan. 2016.

[99] S. W. Lee and H. L. Do, "Boost-Integrated Two-Switch Forward AC-DC LED Driver With High Power Factor and Ripple-Free Output Inductor Current," in IEEE Transactions on Industrial Electronics, vol. 64, no. 7, pp. 5789-5796, July 2017.

[100]M. R. Cosetin, P. C. V. Luz, M. F. da Silva, F. Bisogno, J. M. Alonso and R. N. do Prado, "Single-stage SEPIC-Buck converter for LED lighting with reduced storage capacitor," IECON 2012 - 38th Annual Conference on IEEE Industrial Electronics Society, Montreal, QC, 2012 , pp. 4597-4603.

[101] Y. Wang, Y. Guan, X. Liang, W. Wang and D. Xu, "Twostage LED street lighting system based on a novel singlestage AC/DC converter," in IET Power Electronics, vol. 7, no. 6, pp. 1374-1383, June 2014.

[102]B. Poorali and E. Adib, "Analysis of the Integrated SEPICFlyback Converter as a Single-Stage Single-Switch PowerFactor-Correction LED Driver," in IEEE Transactions on Industrial Electronics, vol. 63, no. 6, pp. 3562-3570, June 2016.

[103]Y. Wang, S. Zhang, J. M. Alonso, X. Liu and D. Xu, "A Single-Stage LED Driver With High-Performance Primary-Side-Regulated Characteristic," in IEEE Transactions on Circuits and Systems II: Express Briefs, vol. 65, no. 1, pp. 76-80, Jan. 2018.

[104] Y. Wang, N. Qi, Y. Guan, C. Cecati and D. Xu, "A SingleStage LED Driver Based on SEPIC and LLC Circuits," in IEEE Transactions on Industrial Electronics, vol. 64, no. 7, pp. 5766-5776, July 2017.

[105]Y. Wang, J. Huang, G. Shi, W. Wang and D. Xu, "A Single-Stage Single-Switch LED Driver Based on the Integrated SEPIC Circuit and Class-E Converter," in IEEE Transactions on Power Electronics, vol. 31, no. 8, pp. 5814-5824, Aug. 2016.

[106]P. L. Wong and F. C. Lee, "A novel concept in integrating PFC and DC/DC converters," in Proc. CPES Annu. Seminar, 2000, pp. 274-281.

[107]J. R. de Britto, A. E. Demian, L. C. de Freitas, V. J. Farias, E. A. A. Coelho and J. B. Vieira, "A proposal of Led Lamp Driver for universal input using Cuk converter," 2008 IEEE Power Electronics Specialists Conference, Rhodes, 2008, pp. 2640-2644.

[108]G. M. Soares, P. S. Almeida, D. P. Pinto and H. A. C. Braga, "A single-stage high efficiency long-life off-line LED driver based on the DCM Cuk converter," IECON 2012 - 38th Annual Conference on IEEE Industrial Electronics Society, Montreal, QC, 2012, pp. 4509-4514.
[109]M. Bodetto, A. Marcos-Pastor, A. El Aroudi, A. Cid-Pastor and E. Vidal-Idiarte, "Modified Ćuk converter for highperformance power factor correction applications," in IET Power Electronics, vol. 8, no. 10, pp. 2058-2064, 102015.

[110]M. Bodetto, A. E. Aroudi, A. Cid-Pastor and M. S. AlNumay, "Improving the Dimming Performance of LowPower Single-Stage AC-DC HBLED Drivers," in IEEE Transactions on Industrial Electronics, vol. 64, no. 7, pp. 5797-5806, July 2017.

[111]H. J. Chiu, Y. K. Lo, J. T. Chen, S. J. Cheng, C. Y. Lin and S. C. Mou, "A High-Efficiency Dimmable LED Driver for Low-Power Lighting Applications," in IEEE Transactions on Industrial Electronics, vol. 57, no. 2, pp. 735-743, Feb. 2010.

[112]C. L. Shen, Y. E. Wu and C. T. Tsai, "Coupled-inductor Sepic-type PFC with soft-switching feature for LED lighting applications," 2011 6th IEEE Conference on Industrial Electronics and Applications, Beijing, 2011, pp. 2384-2389.

[113]M. Bodetto, A. El Aroudi, A. Cid-Pastor, J. Calvente and L. Martínez-Salamero, "Design of AC-DC PFC HighOrder Converters With Regulated Output Current for LowPower Applications," in IEEE Transactions on Power Electronics, vol. 31, no. 3, pp. 2012-2025, March 2016.

[114]A. Shrivastava, B. Singh and S. Pal, "A Novel WallSwitched Step-Dimming Concept in LED Lighting Systems Using PFC Zeta Converter," in IEEE Transactions on Industrial Electronics, vol. 62, no. 10, pp. 6272-6283, Oct. 2015.

[115]M. Brkovic and S. Cuk, "Input current shaper using Cuk converter," Telecommunications Energy Conference, 1992. INTELEC '92., 14th International, Washington, DC, 1992, pp. 532-539.

[116]S. Dian, X. Wen, X. Deng and S. Zhang, "Digital control of isolated Cuk power factor correction converter under wide range of load variation," in IET Power Electronics, vol. 8, no. 1, pp. 142-150, 12015.

[117]C. S. Wong, K. H. Loo, Y. M. Lai, M. H. L. Chow and C. K. Tse, "An Alternative Approach to LED Driver Design Based on High-Voltage Driving," in IEEE Transactions on Power Electronics, vol. 31, no. 3, pp. 2465-2475, March 2016.

[118]A. Leon-Masich, H. Valderrama-Blavi, J. M. BosqueMoncusí and L. Martínez-Salamero, "A High-Voltage SiCBased Boost PFC for LED Applications," in IEEE Transactions on Power Electronics, vol. 31, no. 2, pp. 1633-1642, Feb. 2016.

[119]J. M. Alonso et al., "Reducing storage capacitance in offline LED power supplies by using integrated converters," 2012 IEEE Industry Applications Society Annual Meeting, Las Vegas, NV, 2012, pp. 1-8.

[120]A. J. Calleja, J. M. Alonso, E. Lopez, J. Ribas, J. A. Martinez and M. Rico-Secades, "Analysis and experimental results of a single-stage high-power-factor electronic ballast based on flyback converter," in IEEE 
Transactions on Power Electronics, vol. 14, no. 6, pp. 9981006, Nov 1999.

[121]Y. Wang, Y. Guan, J. Huang, W. Wang and D. Xu, "A Single-Stage LED Driver Based on Interleaved BuckBoost Circuit and LLC Resonant Converter," in IEEE Journal of Emerging and Selected Topics in Power Electronics, vol. 3, no. 3, pp. 732-741, Sept. 2015.

[122] Y. C. Li and C. L. Chen, "A Novel Single-Stage HighPower-Factor AC-to-DC LED Driving Circuit With Leakage Inductance Energy Recycling," in IEEE Transactions on Industrial Electronics, vol. 59, no. 2, pp. 793-802, Feb. 2012.

[123]J. M. Alonso, J. Vina, D. G. Vaquero, G. Martinez and R. Osorio, "Analysis and Design of the Integrated Double Buck-Boost Converter as a High-Power-Factor Driver for Power-LED Lamps," in IEEE Transactions on Industrial Electronics, vol. 59, no. 4, pp. 1689-1697, April 2012.

[124]H. L. Cheng and C. W. Lin, "Design and Implementation of a High-Power-Factor LED Driver With Zero-Voltage Switching-On Characteristics," in IEEE Transactions on Power Electronics, vol. 29, no. 9, pp. 4949-4958, Sept. 2014.

[125]H. L. Cheng, Y. N. Chang, C. A. Cheng, C. H. Chang and Y. H. Lin, "High-power-factor dimmable LED driver with low-frequency pulse-width modulation," in IET Power Electronics, vol. 9, no. 10, pp. 2139-2146, 8172016.

[126]Y. Wang, J. Huang, W. Wang and D. Xu, "A Single-Stage Single-Switch LED Driver Based on Class-E Converter," in IEEE Transactions on Industry Applications, vol. 52, no. 3, pp. 2618-2626, May-June 2016.

[127]K. Modepalli and L. Parsa, "Lighting Up with a DualPurpose Driver: A Viable Option for a Light-Emitting Diode Driver for Visible Light Communication," in IEEE Industry Applications Magazine, vol. 23, no. 2, pp. 51-61, March-April 2017.

[128]B. Poorali, E. Adib and H. Farzanehfard, "A Single-Stage Single-Switch Soft-Switching Power-Factor-Correction LED Driver," in IEEE Transactions on Power Electronics, vol. 32, no. 10, pp. 7932-7940, Oct. 2017.

[129]D. Gacio, J. M. Alonso, A. J. Calleja, J. Garcia and M. Rico-Secades, "A Universal-Input Single-Stage HighPower-Factor Power Supply for HB-LEDs Based on Integrated Buck-Flyback Converter," in IEEE Transactions on Industrial Electronics, vol. 58, no. 2, pp. 589-599, Feb. 2011.

[130]J. C. W. Lam and P. K. Jain, "Isolated AC/DC Offline High Power Factor Single-Switch LED Drivers Without Electrolytic Capacitors," in IEEE Journal of Emerging and Selected Topics in Power Electronics, vol. 3, no. 3, pp. 679-690, Sept. 2015.

[131]J. Liu, H. Tian, G. Liang and J. Zeng, "A Bridgeless Electrolytic Capacitor-Free LED Driver Based on Seriesresonant Converter with Constant Frequency Control," in IEEE Transactions on Power Electronics.
[132]H. Wu, S. C. Wong, C. K. Tse and Q. Chen, "A PFC Single-Coupled-Inductor Multiple-Output LED Driver Without Electrolytic Capacitor," in IEEE Transactions on Power Electronics.

[133]X. Liu, X. Li, Q. Zhou and J. Xu, "Flicker-Free Single Switch Multi-String LED Driver With High Power Factor and Current Balancing," in IEEE Transactions on Power Electronics.

[134]V. J. Thottuvelil, T. G. Wilson and H. A. Owen, "Analysis and design of a push-pull current-fed converter," 1981 IEEE Power Electronics Specialists Conference, Boulder, Colorado, USA, 1981, pp. 192-203.

[135]E. X. Yang, Y. Jiang, G. Hua and F. C. Lee, "Isolated boost circuit for power factor correction," Proceedings Eighth Annual Applied Power Electronics Conference and Exposition,, San Diego, CA, 1993, pp. 196-203.

[136]I. Castro, K. Martin, A. Vazquez, M. Arias, D. G. Lamar and J. Sebastian, "An AC-DC PFC Single-Stage Dual Inductor Current-Fed Push-Pull for HB-LED Lighting Applications," in IEEE Journal of Emerging and Selected Topics in Power Electronics, vol. 6, no. 1, pp. 255-266, March 2018.

[137]N. Q. Trong, H. j. Chiu, Y. k. Lo, C. y. Lin and M. M. Alam, "Modified current-fed full-bridge isolated power factor correction converter with low-voltage stress," in IET Power Electronics, vol. 7, no. 4, pp. 861-867, April 2014.

[138]A. Mohamadi and E. Afjei, "A single-stage high power factor LED driver in continuous conduction mode," The 6th Power Electronics, Drive Systems \& Technologies Conference (PEDSTC2015), Tehran, 2015, pp. 462-467.

[139]Q. Hu and R. Zane, "Minimizing Required Energy Storage in Off-Line LED Drivers Based on Series-Input Converter Modules," in IEEE Transactions on Power Electronics, vol. 26, no. 10, pp. 2887-2895, Oct. 2011.

[140]S. Wang, X. Ruan, K. Yao, S. C. Tan, Y. Yang and Z. Ye, "A Flicker-Free Electrolytic Capacitor-Less AC-DC LED Driver," in IEEE Transactions on Power Electronics, vol. 27, no. 11, pp. 4540-4548, Nov. 2012.

[141]K. W. Lee, Y. H. Hsieh and T. J. Liang, "A current ripple cancellation circuit for electrolytic capacitor-less AC-DC LED driver," 2013 Twenty-Eighth Annual IEEE Applied Power Electronics Conference and Exposition (APEC), Long Beach, CA, 2013, pp. 1058-1061.

[142] Y. Zhang and K. Jin, "A single-stage electrolytic capacitorless AC/DC LED driver," 2014 International Power Electronics and Application Conference and Exposition, Shanghai, 2014, pp. 881-886.

[143]Y. Yang, X. Ruan, L. Zhang, J. He and Z. Ye, "FeedForward Scheme for an Electrolytic Capacitor-Less AC/DC LED Driver to Reduce Output Current Ripple," in IEEE Transactions on Power Electronics, vol. 29, no. 10, pp. 5508-5517, Oct. 2014.

[144]J. He, X. Ruan and L. Zhang, "Adaptive Voltage Control for Bidirectional Converter in Flicker-Free Electrolytic Capacitor-Less AC-DC LED Driver," in IEEE 
Transactions on Industrial Electronics, vol. 64, no. 1, pp. 320-324, Jan. 2017.

[145]U. Ramanjaneya Reddy and B. L. Narasimharaju, "Singlestage electrolytic capacitor less non-inverting buck-boost PFC based AC-DC ripple free LED driver," in IET Power Electronics, vol. 10, no. 1, pp. 38-46, 1202017.

[146]P. Fang, B. Sheng, W. Sam, Y. Zhang and Y. Liu, "LED Driver Achieves Electrolytic Capacitor-Less and FlickerFree Operation with an Energy Buffer Unit," in IEEE Transactions on Power Electronics.

[147]C. A. Cheng, H. L. Cheng, F. L. Yang and C. W. Ku, "Single-stage driver for supplying high-power lightemitting-diodes with universal utility-line input voltages," in IET Power Electronics, vol. 5, no. 9, pp. 1614-1623, November 2012.

[148]D. Camponogara, G. F. Ferreira, A. Campos, M. A. Dalla Costa and J. Garcia, "Offline LED Driver for Street Lighting With an Optimized Cascade Structure," in IEEE Transactions on Industry Applications, vol. 49, no. 6, pp. 2437-2443, Nov.-Dec. 2013.

[149]D. Camponogara, D. R. Vargas, M. A. Dalla Costa, J. M. Alonso, J. Garcia and T. Marchesan, "Capacitance Reduction With An Optimized Converter Connection Applied to LED Drivers," in IEEE Transactions on Industrial Electronics, vol. 62, no. 1, pp. 184-192, Jan. 2015.

[150]Y. Qiu, L. Wang, H. Wang, Y. F. Liu and P. C. Sen, "Bipolar Ripple Cancellation Method to Achieve SingleStage Electrolytic-Capacitor-Less High-Power LED Driver," in IEEE Journal of Emerging and Selected Topics in Power Electronics, vol. 3, no. 3, pp. 698-713, Sept. 2015.

[151]P. Fang, Y. F. Liu and P. C. Sen, "A Flicker-Free SingleStage Offline LED Driver With High Power Factor," in IEEE Journal of Emerging and Selected Topics in Power Electronics, vol. 3, no. 3, pp. 654-665, Sept. 2015.

[152]H. Valipour, G. Rezazadeh and M. R. Zolghadri, "FlickerFree Electrolytic Capacitor-Less Universal Input Offline LED Driver With PFC," in IEEE Transactions on Power Electronics, vol. 31, no. 9, pp. 6553-6561, Sept. 2016.

[153]H. Dong, X. Xie, L. Jiang, Z. Jin and X. Zhao, "An Electrolytic Capacitor-Less High Power Factor LED Driver Based on a "One-and-a-Half Stage" ForwardFlyback Topology," in IEEE Transactions on Power Electronics, vol. 33, no. 2, pp. 1572-1584, Feb. 2018.

[154]Z. Shan, X. Chen, J. Jatskevich (GAE) and C. K. Tse, "An AC-DC LED Driver with an Additional Active Rectifier and a Unidirectional Auxiliary Circuit for AC Power Ripple Isolation," in IEEE Transactions on Power Electronics.

[155]P. Fang, Y. j. Qiu, H. Wang and Y. F. Liu, "A Single-Stage Primary-Side-Controlled Off-line Flyback LED Driver With Ripple Cancellation," in IEEE Transactions on Power Electronics, vol. 32, no. 6, pp. 4700-4715, June 2017.

[156]Jindong Zhang, M. M. Jovanovic and F. C. Lee, "Comparison between CCM single-stage and two-stage boost PFC converters," Applied Power Electronics Conference and Exposition, 1999. APEC '99. Fourteenth Annual, Dallas, TX, 1999, pp. 335-341 vol.1.

[157]P. Fang, W. Sam, Y. Liu and P. C. Sen, "Single-stage LED Driver Achieves Electrolytic Capacitor-less and Flickerfree Operation with Unidirectional Current Compensator," in IEEE Transactions on Power Electronics.

[158]H. Ma, J. (. Lai, C. Zheng and P. Sun, "A High-Efficiency Quasi-Single-Stage Bridgeless Electrolytic Capacitor-Free High-Power AC-DC Driver for Supplying Multiple LED Strings in Parallel," in IEEE Transactions on Power Electronics, vol. 31, no. 8, pp. 5825-5836, Aug. 2016.

[159]M. Arias, D. G. Lamar, J. Sebastian, D. Balocco and A. A. Diallo, "High-Efficiency LED Driver Without Electrolytic Capacitor for Street Lighting," in IEEE Transactions on Industry Applications, vol. 49, no. 1, pp. 127-137, Jan.Feb. 2013.

[160]X. Xie, M. Ye, Y. Cai and J. Wu, "An optocouplerless twostage high power factor LED driver," 2011 Twenty-Sixth Annual IEEE Applied Power Electronics Conference and Exposition (APEC), Fort Worth, TX, 2011, pp. 2078-2083.

[161]L. Huber, Y. Jang and M. M. Jovanovic, "Performance Evaluation of Bridgeless PFC Boost Rectifiers," in IEEE Transactions on Power Electronics, vol. 23, no. 3, pp. 1381-1390, May 2008.

[162]A. Jha and B. Singh, "Modified bridgeless landsman PFC converter for LED driver," 2016 7th India International Conference on Power Electronics (IICPE), Patiala, India, 2016, pp. 1-6.

[163]L. Török and S. Munk-Nielsen, "Efficiency and hardware comparison of analog control-based and digital controlbased $70 \mathrm{~W}$ two-stage power factor corrector and DC-DC converters," Proceedings of the 2011 14th European Conference on Power Electronics and Applications, Birmingham, 2011, pp. 1-8.

[164]C. Y. Wu, T. F. Wu, J. R. Tsai, Y. M. Chen and C. C. Chen, "Multistring LED Backlight Driving System for LCD Panels With Color Sequential Display and Area Control," in IEEE Transactions on Industrial Electronics, vol. 55, no. 10, pp. 3791-3800, Oct. 2008.

[165] W. Y. Choi, J. M. Kwon and B. H. Kwon, "Efficient LED back-light power supply for liquid-crystal-display," in IET Electric Power Applications, vol. 1, no. 2, pp. 133-142, March 2007.

[166]M. Arias, D. G. Lamar, F. F. Linera, D. Balocco, A. Aguissa Diallo and J. Sebastián, "Design of a SoftSwitching Asymmetrical Half-Bridge Converter as Second Stage of an LED Driver for Street Lighting Application," in IEEE Transactions on Power Electronics, vol. 27, no. 3, pp. 1608-1621, March 2012.

[167]M. Arias, M. Fernández Diaz, D. G. Lamar, D. Balocco, A. Aguissa Diallo and J. Sebastián, "High-Efficiency Asymmetrical Half-Bridge Converter Without Electrolytic Capacitor for Low-Output-Voltage AC-DC LED Drivers," 
in IEEE Transactions on Power Electronics, vol. 28, no. 5, pp. 2539-2550, May 2013.

[168]M. Arias, M. F. Diaz, J. E. R. Cadierno, D. G. Lamar and J. Sebastián, "Digital Implementation of the Feedforward Loop of the Asymmetrical Half-Bridge Converter for LED Lighting Applications," in IEEE Journal of Emerging and Selected Topics in Power Electronics, vol. 3, no. 3, pp. 642-653, Sept. 2015.

[169]E. Mujjalinvimut, P. Navaratana $\mathrm{Na}$ Ayudhya and A. Sangswang, "An Improved Asymmetrical Half-Bridge Converter With Self-Driven Synchronous Rectifier for Dimmable LED Lighting," in IEEE Transactions on Industrial Electronics, vol. 63, no. 2, pp. 913-925, Feb. 2016.

[170]M. Arias, I. Castro, D. G. Lamar, A. Vázquez and J. Sebastián, "Optimized design of a high input-voltageripple-rejection converter for LED lighting," in IEEE Transactions on Power Electronics, vol. PP, no. 99, pp. 11.

[171]G. Sauerlander, D. Hente, H. Radermacher, E. Waffenschmidt and J. Jacobs, "Driver Electronics for LEDs," Conference Record of the 2006 IEEE Industry Applications Conference Forty-First IAS Annual Meeting, Tampa, FL, 2006, pp. 2621-2626.

[172]Y. K. Lo, K. H. Wu, K. J. Pai and H. J. Chiu, "Design and Implementation of RGB LED Drivers for LCD Backlight Modules," in IEEE Transactions on Industrial Electronics, vol. 56, no. 12, pp. 4862-4871, Dec. 2009.

[173]X. Wu, J. Zhang and Z. Qian, "A Simple Two-Channel LED Driver With Automatic Precise Current Sharing," in IEEE Transactions on Industrial Electronics, vol. 58, no. 10, pp. 4783-4788, Oct. 2011.

[174]W. Y. Choi, "A Highly Power-Efficient LED Back-Light Power Supply for LCD Display," in Journal of Display Technology, vol. 9, no. 5, pp. 382-387, May 2013.

[175]W. Feng, F. C. Lee and P. Mattavelli, "Optimal Trajectory Control of LLC Resonant Converters for LED PWM Dimming," in IEEE Transactions on Power Electronics, vol. 29, no. 2, pp. 979-987, Feb. 2014.

[176]S. Zhao, J. Xu and O. Trescases, "Burst-Mode Resonant LLC Converter for an LED Luminaire With Integrated Visible Light Communication for Smart Buildings," in IEEE Transactions on Power Electronics, vol. 29, no. 8, pp. 4392-4402, Aug. 2014.

[177]S. Pervaiz, A. Kumar and K. K. Afridi, "GaN-Based HighPower-Density Electrolytic-Free Universal Input LED Driver," in IEEE Transactions on Industry Applications.

[178]S. Pervaiz, A. Kumar and K. K. Afridi, "A Compact Electrolytic-Free Two-Stage Universal Input Offline LED Driver with Volume Optimized SSC Energy Buffer," in IEEE Journal of Emerging and Selected Topics in Power Electronics.

[179]M. F. Menke, R. V. Tambara, F. E. Bisogno, M. F. da Silva and Á. R. Seidel, "Two-stage digitally controlled led driver based on buck-boost and DC/DC LLC resonant converter," 2016 12th IEEE International Conference on Industry Applications (INDUSCON), Curitiba, 2016, pp. $1-8$.

[180]W. Ma, X. Xie and S. Jiang, "LLC resonant converter with variable resonant inductor for wide LED dimming range," 2017 IEEE Applied Power Electronics Conference and Exposition (APEC), Tampa, FL, 2017, pp. 2950-2957.

[181]X. Chen, D. Huang, Q. Li and F. C. Lee, "Multichannel LED Driver With CLL Resonant Converter," in IEEE Journal of Emerging and Selected Topics in Power Electronics, vol. 3, no. 3, pp. 589-598, Sept. 2015.

[182]K. H. Loo, Y. M. Lai and C. K. Tse, "Design and Analysis of LCC Resonant Network for Quasi-Lossless Current Balancing in Multistring AC-LED Array," in IEEE Transactions on Power Electronics, vol. 28, no. 2, pp. 1047-1059, Feb. 2013.

[183]Y. Wang, Y. Guan, D. Xu and W. Wang, "A CLCL Resonant DC/DC Converter for Two-Stage LED Driver System," in IEEE Transactions on Industrial Electronics, vol. 63, no. 5, pp. 2883-2891, May 2016.

[184]Q. Hu and R. Zane, "LED Driver Circuit with Series-InputConnected Converter Cells Operating in Continuous Conduction Mode," in IEEE Transactions on Power Electronics, vol. 25, no. 3, pp. 574-582, March 2010.

[185]W. Chen and S. Y. R. Hui, "A Dimmable Light-Emitting Diode (LED) Driver With Mag-Amp Postregulators for Multistring Applications," in IEEE Transactions on Power Electronics, vol. 26, no. 6, pp. 1714-1722, June 2011.

[186]J. Liu, W. Sun and J. Zeng, "Precise current sharing control for multi-channel LED driver based on switch-controlled capacitor," in IET Power Electronics, vol. 10, no. 3, pp. 357-367, 3102017.

[187]X. Qu, S. C. Wong and C. K. Tse, "Noncascading Structure for Electronic Ballast Design for Multiple LED Lamps With Independent Brightness Control," in IEEE Transactions on Power Electronics, vol. 25, no. 2, pp. 331340, Feb. 2010.

[188]R. Zhao and J. Zhang, "High efficiency hybrid current balancing method for multi-channel LED drive," 2015 IEEE Applied Power Electronics Conference and Exposition (APEC), Charlotte, NC, 2015, pp. 854-860.

[189]J. Zhang, T. Jiang and X. Wu, "A High-Efficiency QuasiTwo-Stage LED Driver With Multichannel Outputs," in IEEE Transactions on Industrial Electronics, vol. 64, no. 7, pp. 5875-5882, July 2017.

[190]C. C. Chen, C. Y. Wu, Y. M. Chen and T. F. u, "Sequential Color LED Backlight Driving System for LCD Panels," in IEEE Transactions on Power Electronics, vol. 22, no. 3, pp. 919-925, May 2007.

[191]P. Chen, H. C. Liu, Y. W. Yang, Y. Y. Li and F. Budiman, "A multi-channel high precision current matching LED Driver for intelligent dimming," 2015 International Symposium on Intelligent Signal Processing and Communication Systems (ISPACS), Nusa Dua, 2015, pp. 174-177. 
[192]C. L. Kuo, T. J. Liang, K. H. Chen and J. F. Chen, "Design and implementation of high frequency AC-LED driver with digital dimming," Proceedings of 2010 IEEE International Symposium on Circuits and Systems, Paris, 2010, pp. 3713-3716.

[193]B. G. Kang, Y. Choi and S. K. Chung, "High frequency AC-LED driving for street light," 2015 9th International Conference on Power Electronics and ECCE Asia (ICPEECCE Asia), Seoul, 2015, pp. 1246-1251.

[194]M. S. Lin and C. L. Chen, "An LED Driver With Pulse Current Driving Technique," in IEEE Transactions on Power Electronics, vol. 27, no. 11, pp. 4594-4601, Nov. 2012.

[195]J. C. W. Lam and P. K. Jain, "A High Power Factor, Electrolytic Capacitor-Less AC-Input LED Driver Topology With High Frequency Pulsating Output Current," in IEEE Transactions on Power Electronics, vol. 30, no. 2, pp. 943-955, Feb. 2015.

[196]M. A. Juárez, P. R. Martínez, G. Vázquez, J. M. Sosa and M. Ponce, "Analysis and design for self-oscillating LED driver with high frequency pulsating output current," IECON 2015 - 41st Annual Conference of the IEEE Industrial Electronics Society, Yokohama, 2015, pp. 003992-003996.

[197]I. Castro, S. Lopez, K. Martin, M. Arias, D. G. Lamar and J. Sebastian, "A family of high frequency AC-LED drivers based on ZCS-QRCs," in IEEE Transactions on Power Electronics.

[198]S. Moon, G. B. Koo and G. W. Moon, "A New Control Method of Interleaved Single-Stage Flyback AC-DC Converter for Outdoor LED Lighting Systems," in IEEE Transactions on Power Electronics, vol. 28, no. 8, pp. 4051-4062, Aug. 2013.

[199]H. Cheng, Y. Chang, C. Chang, S. Hsieh and C. Cheng, "A Novel High-Power-Factor AC/DC LED Driver with Dual Flyback Converters," in IEEE Journal of Emerging and Selected Topics in Power Electronics.

[200]C. A. Cheng, H. L. Cheng, C. H. Chang, F. L. Yang and T. Y. Chung, "A single-stage LED driver for street-lighting applications with interleaving PFC feature," 2013 International Symposium on Next-Generation Electronics, Kaohsiung, 2013, pp. 150-152.

[201]C. A. Cheng, C. H. Chang, H. L. Cheng and C. H. Tseng, "A novel single-stage LED driver with coupled inductors and interleaved PFC," 2015 9th International Conference on Power Electronics and ECCE Asia (ICPE-ECCE Asia), Seoul, 2015, pp. 1240-1245.

[202]P. Zumel, C. Fernandez, M. Sanz, A. Lazaro and A. Barrado, "HBLED driving strategy with reduced storage capacitor based on load modularization," 2011 TwentySixth Annual IEEE Applied Power Electronics Conference and Exposition (APEC), Fort Worth, TX, 2011, pp. 728734.

[203]L. Huber, B. T. Irving and M. M. Jovanovic, "Open-Loop Control Methods for Interleaved DCM/CCM Boundary
Boost PFC Converters," in IEEE Transactions on Power Electronics, vol. 23, no. 4, pp. 1649-1657, July 2008.

[204]L. Huber, B. T. Irving and M. M. Jovanovic, "Review and Stability Analysis of PLL-Based Interleaving Control of DCM/CCM Boundary Boost PFC Converters," in IEEE Transactions on Power Electronics, vol. 24, no. 8, pp. 1992-1999, Aug. 2009.

[205]Z. Wang, S. Wang, P. Kong and F. C. Lee, "DM EMI Noise Prediction for Constant On-Time, Critical Mode Power Factor Correction Converters," in IEEE Transactions on Power Electronics, vol. 27, no. 7, pp. 3150-3157, July 2012.

[206]"American National Standard for Electric Power Systems and Equipment-Voltage Ratings $(60 \mathrm{~Hz})$, ANSI C84.12011".

[207]B. Gray, "Demystifying 347V and 480V lighting installations," E Craftsmen, Waterloo, ON, Canada, 2014. [Online]. Available: http:/www.ecraf tsmen.com/blog/demystifying-347v-and-480v-lightinginstallations. Accessed on: Oct. 20, 2015.

[208]GE Lighting, East Cleveland, OH, USA, "480V to $277 \mathrm{~V}$ step-down autotransformers for applications up to 375 watts, " 2013.

[209] M. R. Mendonça, E. Mineiro; Sá, R. P. Coutinho and F. L. M. Antunes, "AC-DC single-switch three-phase converter with peak current control for power LEDs," 2014 11th IEEE/IAS International Conference on Industry Applications, Juiz de Fora, 2014, pp. 1-6.

[210]R. P. Coutinho, K. C. A. de Souza, F. L. M. Antunes and E. Mineiro Sá, "Three-Phase Resonant Switched Capacitor LED Driver With Low Flicker," in IEEE Transactions on Industrial Electronics, vol. 64, no. 7, pp. 5828-5837, July 2017.

[211]A. R. Prasad, P. D. Ziogas and S. Manias, "An active power factor correction technique for three-phase diode rectifiers," in IEEE Transactions on Power Electronics, vol. 6, no. 1, pp. 83-92, Jan 1991.

[212]E. Ismail and R. W. Erickson, "A single transistor three phase resonant switch for high quality rectification," Power Electronics Specialists Conference, 1992. PESC '92 Record., 23rd Annual IEEE, Toledo, 1992, pp. 1341-1351 vol.2.

[213]D. S. L. Simonetti, J. Sebastian, and J. Uceda, "Singleswitch three-phase power factor preregulator under variable switching frequency and discontinuous input current, " in Proc. 24th Annu. IEEE Power Electron. Spec. Conf., Seattle, WA, USA, 1993, pp. 657-662.

[214]M. S. Dawande and G. K. Dubey, "Programmable input power factor correction method for switch-mode rectifiers," in IEEE Transactions on Power Electronics, vol. 11, no. 4, pp. 585-591, Jul 1996.

[215] Yungtaek Jang and M. M. Jovanovic, "A comparative study of single-switch three-phase high-power-factor rectifiers," in IEEE Transactions on Industry Applications, vol. 34, no. 6, pp. 1327-1334, Nov/Dec 1998. 
[216]K. Yao, X. Ruan, C. Zou and Z. Ye, "Three-phase singleswitch boost power factor correction converter with high input power factor," in IET Power Electronics, vol. 5, no. 7, pp. 1095-1103, August 2012.

[217]J. W. Kolar, H. Ertl and F. C. Zach, "A novel three-phase single-switch discontinuous-mode AC-DC buck-boost converter with high-quality input current waveforms and isolated output," in IEEE Transactions on Power Electronics, vol. 9, no. 2, pp. 160-172, Mar 1994.

[218]J. Minbock and J. W. Kolar, "Design and experimental investigation of a single-switch three-phase flybackderived power factor corrector," INTELEC. TwentySecond International Telecommunications Energy Conference (Cat. No.00CH37131), Phoenix, AZ, 2000, pp. 471-478.

[219]T. J. Omedi and R. Barlik, "Three-phase AC-DC unidirectional PWM multiple-switch rectifier topologiesselected properties and critical evaluation," Proceedings of IEEE International Symposium on Industrial Electronics, Warsaw, 1996, pp. 784-789 vol.2.

[220]B. T. Ooi, J. C. Salmon, J. W. Dixon and A. B. Kulkarni, "A Three-Phase Controlled-Current PWM Converter with Leading Power Factor," in IEEE Transactions on Industry Applications, vol. IA-23, no. 1, pp. 78-84, Jan. 1987.

[221]B. T. Ooi, J. W. Dixon, A. B. Kulkarni and M. Nishimoto, "An integrated AC drive system using a controlled-current PWM rectifier/inverter link," in IEEE Transactions on Power Electronics, vol. 3, no. 1, pp. 64-71, Jan. 1988.

[222]J. W. Dixon and Boon-Teck Ooi, "Indirect current control of a unity power factor sinusoidal current boost type threephase rectifier," in IEEE Transactions on Industrial Electronics, vol. 35, no. 4, pp. 508-515, Nov. 1988.

[223]S. Rajagopalan, D. M. Divan, R. G. Harley and J. R. Mayor, "Variable topology boost-buck converter for maximizing power output from unbalanced electrical generators," 2006 37th IEEE Power Electronics Specialists Conference, Jeju, 2006, pp. 1-7.

[224]Z. Zhang, A. Mallik and A. Khaligh, "A High Step-Down Isolated Three-Phase AC-DC Converter," in IEEE Journal of Emerging and Selected Topics in Power Electronics, vol. 6, no. 1, pp. 129-139, March 2018.

[225]R. F. Brewster and A. H. Barret, "Three phase AC to DC voltage converter with power line harmonic current reduction," U.S. Patent 4143 414, Mar. 6, 1979.
[226]I. Castro, D. G. Lamar, M. Arias, M. M. Hernando and J. Sebastian, "Multicell Three-Phase AC-DC Driver for HBLED Lighting Applications," in IEEE Transactions on Industry Applications, vol. 53, no. 4, pp. 3803-3813, JulyAug. 2017.

[227]I. Castro, D. G. Lamar, M. Arias, J. Sebastián and M. M. Hernando, "Three phase converter with galvanic isolation based on Loss-Free Resistors for HB-LED lighting applications," 2016 IEEE Applied Power Electronics Conference and Exposition (APEC), Long Beach, CA, 2016, pp. 822-829.

[228]M. J. Kocher and R. L. Steigerwald, "An AC-to-DC converter with high quality input waveforms," IEEE Trans. Ind. Appl., vol. IA-19, no. 4, pp. 586-599, Jul. 1983.

[229]S. Singer and A. Fuchs, "Multiphase AC-DC conversion by means of loss-free resistive networks," Inst. Elect. Eng. Proc. - Circuits, Dev. Syst., vol. 143, no. 4, pp. 233-240, Aug. 1996.

[230]U. Kamnarn and V. Chunkag, "Analysis and design of a modular threephase AC-to-DC converter using CUK rectifier module with nearly unity power factor and fast dynamic response," IEEE Trans. Power Electron., vol. 24, no. 8, pp. 2000-2012, Aug. 2009.

[231]G. Tibola and I. Barbi, "Isolated three-phase high power factor rectifier based on the SEPIC converter operating in discontinuous conduction mode," IEEE Trans. Power Electron., vol. 28, no. 11, pp. 4962-4969, Nov. 2013.

[232]G. C. Gallios, "An enchanced technique for reduction of off line converter input harmonics," Proc. of Powercon, vol. 11, 1984, F-2 p. 1-F-2 p. 9.

[233]I. Castro, M. Arias, D. G. Lamar, J. Sebastián and M. M. Hernando, "Modular three-phase ac-dc LED driver based on summing the light output of each phase," 2018 IEEE Applied Power Electronics Conference and Exposition (APEC), San Antonio, TX, 2018.

[234]I. Castro, A. Vazquez, D. G. Lamar, M. Arias, M. M. Hernando and J. Sebastian, "An electrolytic capacitorless modular three-phase ac-dc LED driver based on summing the light output of each phase," in IEEE Journal of Emerging and Selected Topics in Power Electronics.

[235]H. Sun, "Sports Lighting - Design Considerations For The Beijing 2008 Olympic Games", GE Beijing 2008 Olympic Games Solutions, 2008. 


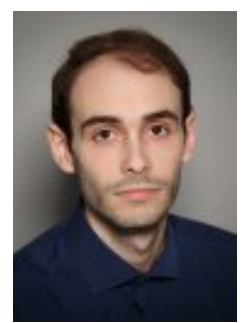

Ignacio Castro (S'14, M'18) was born in Gijón, Spain, in 1989.

He received the M.Sc. degree in telecommunication engineering and the $\mathrm{Ph} . \mathrm{D}$. in electrical engineering from the University of Oviedo, Gijón, Spain, in 2014 and 2018, respectively.

From 2014 to 2018 , he has been a research assistant and member of the power supply group in the University of Oviedo.

In August 2018, he joined United Technologies Research Centre in Ireland as a Senior Research Engineer.

His research interests include low and medium power dc$\mathrm{dc}$ converters, modeling, simulation and control of dc-dc converters and power-factor correction ac- $\mathrm{dc}$ converters.

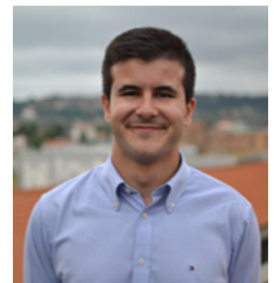

Aitor Vazquez (S'2010, M'2015) was born in Oviedo, Spain, in 1984. He received the M.Sc. degree in telecommunication engineering, in 2009 , and the $\mathrm{PhD}$. degree in electrical engineering in 2016, from the University of Oviedo, Gijon, Spain.

He became a Member of the Power Supply System Group, University of Oviedo, in 2010. His current research interests include modularization techniques applied

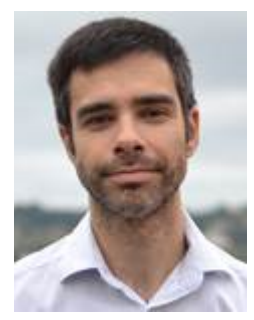

Manuel Arias (S'05 M'10) received the M. Sc. degree in electrical engineering from the University of Oviedo, Spain, in 2005 and the $\mathrm{Ph}$. D. degree from the same university in 2010 .

In 2007 he joined the University of Oviedo as an Assistant Professor and since 2016 he is an Associate Professor at the same university.

His research interests include ac-dc and dc-dc power converters, battery-cell equalizers and LED lighting.

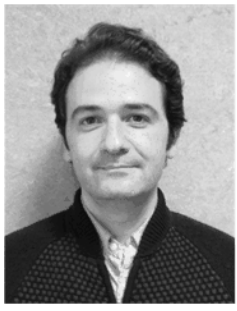

Diego G. Lamar (S'05-M'08-SM'18) was born in Zaragoza, Spain, in 1974. He received the M.Sc. and Ph.D. degrees in electrical engineering from the Universidad de Oviedo, Gijón, Spain, in 2003 and 2008, respectively.

In 2003 and 2005 he became a Research Engineer and an Assistant Professor respectively at the University of Oviedo. Since September 2011, he has been an Associate Professor. His research interests are focused in switching-mode power supplies, converter modelling, and power-factor-correction converters.

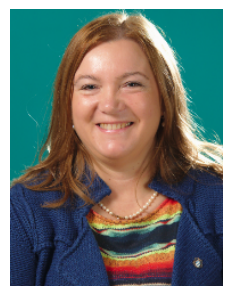

Marta M. Hernando (M'95-SM'11) was born in Gijón, Spain, in 1964. She received the M.Sc. and Ph.D. degrees in Electrical Engineering from the University of Oviedo, Gijón, Spain, in 1988 and 1992, respectively. She is currently a Professor at the University of Oviedo. Her main research interests include switching-mode power supplies and high-power factor rectifiers.

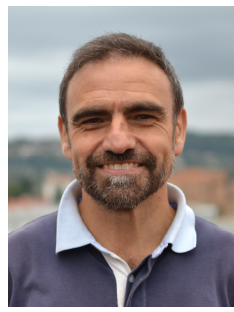

Javier Sebastián (M'87-SM'11) was born in Madrid, Spain, in 1958. He received the M.Sc. degree from the Technical University of Madrid (UPM), and the Ph.D. degree in electrical engineering from the University of Oviedo, Spain, in 1981 and 1985, respectively.

He was an Assistant Professor and an Associate Professor at both the UPM and the University of Oviedo. Since 1992, he has been with the University of Oviedo, where he is currently a Professor. His research interests are switching-mode power supplies, modeling of dc-to-dc converters, low output voltage dc-to-dc converters, high power factor rectifiers, LED drivers, dc-to-dc converters for envelope tracking techniques and the use of wide band-gap semiconductors in power supplies. 